City University of New York (CUNY)

CUNY Academic Works

1974

\title{
Effects of Instructions and Stimulus Representation on Selective Learning in Children
}

Adele E. Gottfried

Graduate Center, City University of New York

\section{How does access to this work benefit you? Let us know!}

More information about this work at: https://academicworks.cuny.edu/gc_etds/1655

Discover additional works at: https://academicworks.cuny.edu

This work is made publicly available by the City University of New York (CUNY).

Contact: AcademicWorks@cuny.edu 


\section{INFORMATION TO USERS}

This material was produced from a microfilm copy of the original document. While the most advanced technological means to photograph and reproduce this document have been used, the quality is heavily dependent upon the quality of the original submitted.

The following explanation of techniques is provided to help you understand markings or patterns which may appear on this reproduction.

1. The sign or "target" for pages apparently lacking from the document photographed is "Missing Page(s)". If it was possible to obtain the missing page(s) or section, they are spliced into the film along with adjacent pages. This may have necessitated cutting thru an image and duplicating adjacent pages to insure you complete continuity.

2. When an image on the film is obliterated with a large round black mark, it is an indication that the photographer suspected that the copy may have moved during exposure and thus cause a blurred image. You will find a good image of the page in the adjacent frame.

3. When a map, drawing or chart, etc., was part of the material being photographed the photographer followed a definite method in "sectioning" the material. It is customary to begin photoing at the upper left hand corner of a large sheet and to continue photoing from left to right in equal sections with a small overlap. If necessary, sectioning is continued again - beginning below the first row and continuing on until complete.

4. The majority of users indicate that the textual content is of greatest value, however, a somewhat higher, quality reproduction could be made from "photographs" if essential to the understanding of the dissertation. Silver prints of "photographs" may be ordered at additional charge by writing the Order Department, giving the catalog number, title, author and specific pages you wish reproduced.

5. PLEASE NOTE: Some pages may have indistinct print. Filmed as received. 
COTTFRIED, Adele Eskeles, 1947-

EFFECTS OF INSTRUCTIONS AND STIMULUS REPRESENTATION ON SELECTIVE LEARNING IN CHILDREN.

The City University of New York, Ph.D., 1975 Psychology, general

Xerox University Microfilms, Ann Arbor, Michigan 48106

(c) 1975

ADELE ESKELES GOTTFRIED

ALL RIGHTS RESERVED 
EFFECTS OF INSTRUCTIONS AND STIMULUS REPRESENTATION ON

\title{
SELECTIVE LEARNING IN CHILDREN
}

by

ADELE E. GOTTFRIED

\begin{abstract}
A dissertation submitted to the Graduate Faculty in Educational Psychology in partial fulfillment of the requirements for the degree of Doctor of Philosophy, The City University of New York.
\end{abstract}


This manuscript has been read and accepted for the Graduate Faculty in Educational Psychology in satisfaction of the dissertation requirement for the degree of Doctor of Philosophy.

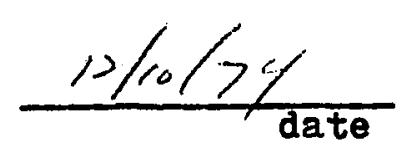

[signature]

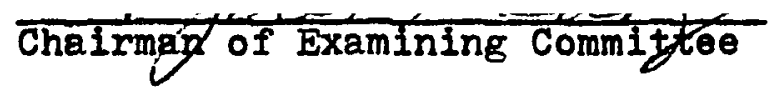

[signature]

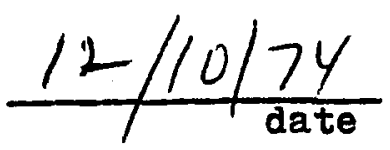

Executive Officer

Dr. Phyllis A. Katz

Dr, Joseph Glick

Dr. Barry Gholson

Supervisory Committee

The City University of New York 


\begin{abstract}
EFFECTS OF INSTRUCTIONS AND STIMULUS REPRESENTATION ON SELECTIVE LEARNING IN CHIIDREN

by
\end{abstract}

Adele E. Gottfried

Adviser, Professor Phyllis A. Katz

Selective learning patterns of children investigated using incidental learning methodology. Since incidental, in contrast to intentional learning occurs in the absence of instructions which prepare the subfect for later retention tests, a subject has riatively more freedom to choose to attend to and learn only a portion of the presented information (thus exercising selectivity). Frevious research suggested that selectivity seemed to increase or decrease with development in relation to different incidental learning paradigms. For studies in which incidental stimuli were presented without a concurrent intentional task (Type 1) incidental learning increased with age indicating decreased selectivity. For studies in which incidental stimuli were presented with a simultaneous intentional task (Type 2) incidental learning remained stable or decreased with age, while concurrent intentional learning increased, indicating increased selectivity. The purpose of the present study was to delineate developmental processes associated with these seemingly divergent trends. In addition, children's selective learning of stimuli corresponding to different developmental levels of cognitive representation had been seriously neglected in the literature. Most investigations employed unrélated stimuli 
which necessitated rote processes for recall. It was also the purpose of this study to determine the influence of stimulus representation upon children's selective learning.

Based upon theory (development of conceptual representation) and empirical trends, it was hypothesized that older children are more flexible in exercising selectivity than younger children. Thus, learning patterns of older but not younger children were expected to be significantly modified by instructional and stimulus variation. To test this hypothesis, a three-way factorial design was employed. The factors weres (a) type of instruction (Type 1 vs. 2), (b) stimulus representation (conceptually-, perceptually- or unrelated). and (c) developmental level (first- and sixth-graders). Subjects were 168 white, middle class children who were randomly assigned to experimental conditions. An equal number of first- and sixth-grade girls and boys were employed. Eight pairs of colored pictures were presented in each condition. The same stimuli were used in all conditions, but were paired conceptually, perceptually or in unrelated manner. In the Type 1 condition subjects were instructed to look at the pictures but were not informed that they would receive later retention tasks. In the Type 2 condition subjects were instructed to look at all stimuli and to remember the top member of each pair for later retention. Free recall and matching of pairs tasks were administered following stimulus exposure to determine the influence of instructions and stimulus representation on learning.

Results revealed that selective learning patterns of 
both age groups were significantly and similarly modified by instructions and stimuli. Incidental learning was significantly superior for subjects in Type 1 compared to those in Type 2 conditions, while learning of the top (intentional--Type 2) stimulus was significantly superior for subjects in Type 2 compared to those in Type 1 conditions. Relative proportions of intentional (top) to total stimulus recall were not significantly different between the grades. Matching performance of subjects in perceptual conditions was significantly superior to that of subjects in conceptual conditions, whose matching was significantly superior to that of subjects in unrelated stimulus conditions. Developmental afferences were related to the level rather than the pattern of retention. Type 1 instructions enhanced sixth-graders' free recall of incidental stimuli and pairs to a significantly greater extent than for first-graders, while Type 2 conditions enhanced first-graders' total stimulus recall to a significantly greater degree than for sixth-graders.

Selectivity did not increase or decrease with age but was related to experimental conditions for all subjects. The resulting developmental differences indicated that relatively nonstructured conditions enhanced older subjects' recall to a greater extent relative to younger subjects, while younger subjects ${ }^{\circ}$ recall was facilitated by relatively structured conditions compared to older subjects. Production deficiency and/or retrieval inefficiencies of younger relative to older children are processes advanced to explain the developmental differences. The similarity of younger and older children's 
use of representation is discussed, as well as the influence of Type 1 and 2 designs on selective learning patterns. A definition of selectivity which accounts for components rather than total amount of learning is proposed. 
Acknowledgements

My deep appreciation is extended to Phyllis A. Katz, committee chairperson, for her valuable guidance and interest throughout the course of this dissertation. I am grateful to Joseph Glick and Barry Gholson for their helpful suggestions, critical comments and for serving on the dissertation committee. Sincere thanks are extended to Gordon Hale and Edith Neimark for serving as readers for the final oral examination.

I also thank my husband and colleague Allen W. Gottfried for his suggestions and encouragement during my dissertation research and graduate studies, and Susan Horn for her assistance.

The cooperation of the faculty and students of the Murray Avenue School in the Mamaroneck School District, Westchester, was essential to carrying out the study. Their participation is sincerely appreciated. Special thanks go to Calvert Schlick, Richard Anderson and Bernard Kessler for their kind support of my research. 
TABLE OF CONTENTS

Page

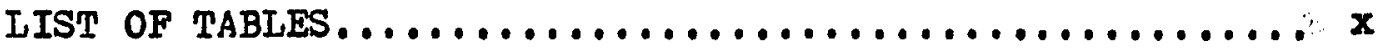

IIST OF FIGURES. ............................

Chapter

I. INTRODUCTION. .......................... 1

Review of Incidental Learning Studies with a Concurrent Intentional Task (Type 2) ...... 6 Review of Incidental Learning Studies without

a Concurrent Intentional Task............18

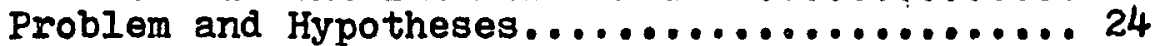

II. METHOD.............................. 31

Design............................ 31

Subjects........................... 31

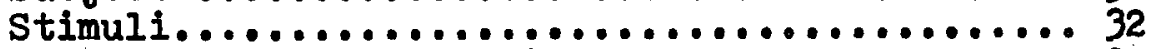

Type of Task Presentation............... 35

Retention Tasks....................... 36

Procedure........................... 37

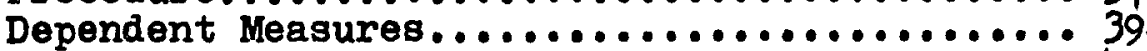

Pretests............................40

III. RESULTS............................ 42

IV. DISCUSSION.......................... 71

The Flexibility Hypothesis.............. 71

Selective Learning Trends................. 86

Other Implications of the Data...............1 01

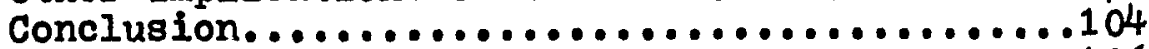

Educational Implications...............106

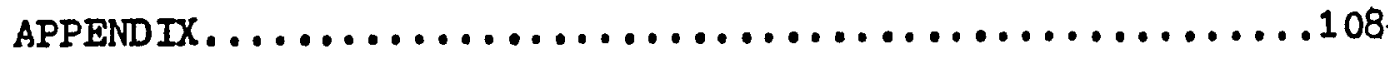

REFERENCES. ...............................127 


\section{LIST OF TABLES}

Table

Page

1 Means for Total Number of Stimuli Recalled

Grouped by Grade and Type.................. 44

2 Mean Number of Incidental Stimuli Recalled

Grouped by Grade and Type..................48.

3 Mean Number of Incidental Stimuli Recalled Grouped

by Grade, Sex and Stimulus................ 51

4. Mean Number of Correctly Matched Pairs Grouped

by Grade, Type and Stimulus............... 56

5 Mean Number of Conceptual Pairs Recalled

Grouped by Type and Stimulus..............59

6 Mean Number of Perceptual Pairs Recalled

Grouped by Type and Stimulus................61

7 Mean Number of Perceptual Pairs Recalled

Grouped by Grade and Type...............6...63

8 Mean Number of Unrelated Pairs Recalled Grouped

by Grade, Type and Stimulus.............. 6.5

9 Mean Number of Within Treatment Pairs Grouped

3y Grade and Type.......................68

A Means and Standard Deviations for Total Amount of

Recalled Grouped by Grade, Type and Stimulus.....110

B Means and Standard Deviations for Number of

Intentional Stimuli Grouped by Grade. Type

and stimulus. 


\section{IIST OF TABLES}

Table

C Means and Standard Deviations for Number of Incidental Stimuli Grouped by Grade, Type and stimulus............................112

D Means and Standard Deviations for the Froportion of Intentional to Total Stimuli Grouped by Grade,

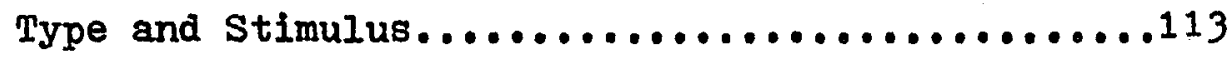

E Means and Standard Deviations for Number of ..

Correctly Matched Pairs Grouped by Grade, Type

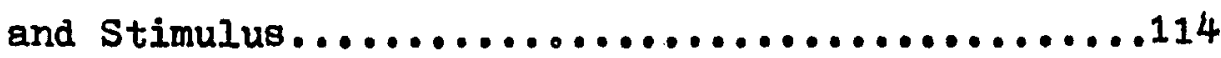

F Means and Standard Deviations for Conceptual Pairs

Recalled Grouped by Grade, Type and Stimulus.....115

G Means and Standard Deviations for Perceptual Pairs

Recalled Grouped by Grade, Type and Stimulus.....116

H Means and Standard Deviations for Unrelated Pairs

Recalled Grouped by Grade, Type and Stimulus.....11\%

I Means and Standard Deviations for Within Treatment

Pairs Recalled Grouped by Grade, Type and

Stimulus. 118

$J$ Means and Standard Deviations for Latency Grouped

by Grade, Type and Stimulus.................119

$K$ Summary of Analyses of Variance $F$ Ratios for

Dependent Variables.......................120

I Mean Number of Matching Errors Grouped by Grade,

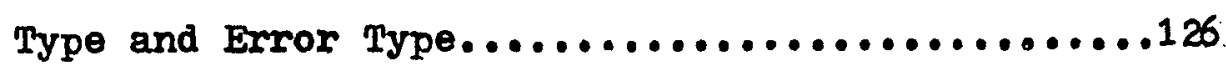




\section{IIST OF FIGURES}

Figure

Page

1 Grade X Type interaction for number of stimuli

$$
\text { recalled.............................. } 45
$$

2 Grade $X$ Type interaction for the number of

incidental stimuli recalled...............4.9

3 Sex $X$ Grade X Stimulus interaction for the

number of incidental stimuli recalled......... 52

4 Main effects for grade, type and stimulus, Total

number of correctly matched pairs.......... 5.7

5 Grade $X$ Type interaction for the number of

within treatment pairs...................69 
CHAPTER I

INTRODUCTION

Interest in incidental learning in children has proliferated during the past few years. Such studies provide an opportunity to investigate the development of selective processes in attention (Hagen \& Hale, 1973) and leaming (Stevenson, 1972). Incidental learning, in contrast to intentional learning, occurs in the absence of instructions which prepare the subject for later retention tests (Postmen, 1964). Therefore, a subject has relatively more freedom to choose to attend to and learn only a portion of the presented information (thus exercising selectivity) in incidental as opposed to intentional learning conditions. According to Postman (1964), instructions "activate responses to the materials" (p. 189) which faciliate learning. Such responses include labeling and rehearsal, among others. Thus, intentional learning should be superior to incidental learning due to the subjects' use of deliberate, organized learning strategies which are activated by instructions. Research with adults has indicated that intentional learning is usually superior to incidental learning (Mclaughlin, 1965, Postman, 1964). Developmental studies, however, have shown that instuctions may not necessarily serve the same roles in the learning of children. 
In some instances, with adult subjects, incidentel learning may be equivalent or even superior to intentional learning. Such is the case when responses to the materials are strengthened through general activities which orient the learner to the materials even in the absence of intentional instructions (McLaughlin, 1965 , Postman, 1964). Such orienting tasks, as they are called, allow the learner to label and/or rehearse stimulus materials without indicating that retention will be tested. For instance, a subject might be asked to rate certain syllables on phonetic similarity without being specifically asked to remember the syllables. It would be expected that subsequent retention would be superior for subjects learning incidental materials with, rather than without, orienting tasks. When orienting tasks are omitted, intentional learning should be superior to incidental learning. Studies of incidental learning conducted with children, however, do not unequivocally demonstrate superior intentional learning relative to incidental learning administered without orienting tasks.

Different theoretical approaches have been advanced to explain the selection processes involved in incidental and intentional learning. The nature of the stimulus is an important source of selectivity in all approaches. Postman (1964) postulates that stimulus characteristics, such as meaningfulness influence subjects ${ }^{\prime}$ responses to the materials (such as labeling and employing associations) which influence incidental and intentional recall. Thus, characteristics of the stimuli affect subjects' selective learning by 
enhancing or diminishing responses produced in relation to such materials. Berlyne (1963), on the other hand, stresses the role of symbolic and cognitive processes related to selectivity in incidental learning, rather than emphasizing verbal and associative processes. According to Berlyne, incidental learning increases when stimuli are characterized by collative properties relative to the individual's symbolic structures. Collative properties, such as novelty, surprise, ox change actively involve the person in a comparison of the stimuli with others also present in the stimulus field, or with those that have been previously encountered and symbolically stored. Therefore, collative stimuli elicit increased attention and thus enhance incidental learning. Though both of these theories may have relevance to adult learning, other processes may be involved in selective learning and attention in children. For example, the ability of children to focus differentially upon intentional and incidental stimuli may increase with development, as well as their ability to represent stimuli symbolically. These latter processes are the focus of the present study. In order to elucidate them, it is necessary to examine the paradigms employed.

In investigating incidental learning in children, two types of methodologies have been used. These paradigms have been referred to by Postman (1964) as Type 1 and Type 2. Type 1 studies are those in which subjects are simply exposed to materials without any specific instructions regarding retention. Following exposure, the subjects' 
retention is tested. Within this paradigm, selection can occur with respect to both the type of material learned and the amount. In contrast, Type 2 studies are those in which subjects are instructed to learn a specific (i.e. intentional) task. Presented simultaneously with the intentional learming stimuli are other stimuli which are incidental to the learning task, and which the subject is not instructed to learn. Within this latter paradigm, the relation of incidental to intentional stimuli may vary. Incidental stimuli may be èther intrinsic or extrinsic to the intentional stimuli. Intrinsic incidental stimuli are presented as integral components of the intentional stimuli, but in a way which seems irrelevant for learning. For example, words to be learned may be printed in various colors, and the color cues will subsequently be used to measure incidental learning. Extrinsic incidental stimuli are typically presented as separate elements of the experimental situation, for example, presenting geometric forms next to words in a list. In all situations, the measure of intentional learning is defined by the instructions, while incidental learning is measured through retention of irrelevant stimuli. Selection in Type 2 tasks has been defined in the' developmental literature as the relative amounts of intentional and incidental stimuli learned by subjects. Type 2 paradigms also allow for the investigation of selective learning of particular stimuli.

Developmental studies of incidental learning have had as their major aim the study of selective attention in children. 
The majority of studies conducted with children have been Type 2 designs using extrinsic incidental stimuli. Selective attention to task-relevant (intentional) and task-irrelevant (incidental) materials is inferred from the children's responses on retention tests. It is thus assumed that selective attention has occurred to the stimuli which are recalled (Hagen \& Hale, 1973). There is a problem in this asgumption, however. Since tests of retention involve memory, and since memory itself is affected by learning, it is not at all evident that selectivity in children's incidental learning is due to attention rather than memory. However, using different types of retention tests may tap processes which are differentially sensitive to attention and memory. Within incidental learning studies, recognition and recall tests have demonstrated different patterns of retention (McLaughlin, 1965: Siegel \& Corsini, 1969, von Wright, 1973). Recognition tasks appear to be more sensitive to attention, whereas recall may be more sensitive to memory factors (Siegel \& Corsini, 1969).

Not all reviews of children's incidental learning have differentiated the literature according to type of methodology employed (e.g. Hagen \& Hale, 1973; Stevenson, 1970). Failure to do this has resul.ted in contradictory developmental trends. In some instances, for example, no change or decreases in amount of incidental learning have occurred with age (Maccoby \& Hagen,. 1965, Hagen, 1967). In other studies curvilinear relationships with age have been found (Siegel \& Stevenson, 1965), and increases with age have also been obtained (Vaughan, 1968). Such disparate findings become more coherent when the 
particular methodolgy employed is taken into consideration. The next portion of this paper will review the developmental trends obtained in children's incidental learning, as they have been found with Type 1 and Type 2 methodologies delineated above. 1

Review of Incidental Learning Studies with a Concurrent Intentional Task (Type 2)

Type 2 developmental studies of incidental learning appear to yield different patterns of selective learning than studies using Type 1 methodology. Selectivity may be defined as learning particular stimuli at the expense. of others. Learning may be more or less selective on a variety of dimensions one of which is the total amount of learning. For this dimension, the greater the total amount of learning, the less the degree of selectivity manifested. This position stems from two sources. First, Postman (1964) states that incidental learning is more selective than intentional learning since responses are less likely to be made to as many of the stimuli in the former as in the latter. Thus, overall amount of learning is likely to be lower in incidental than intentional learning. Generalizing

1Since the majority of developmental studies have employed Type 2 methodology, this paradigm will be reviewed first. Trenas from these studies will form a basis for comparison with Type 1 studies. The designations of Type 1 and Type 2 will be used to refer to the paradigms as defined above. 
from this position, in incidental learning decreased learning denotes increased selectivity. Second, the word selection itself implies that learning "more" is global rather than particular.

A second dimension in which selectivity may be manifested relates to the nature of the incidental materials. Stimuli may vary with regard to their correspondence with children's cognitive abilities and/or learning strategies. Thus, children of different developmental levels may be inclined to selectively learn some types of materials more readily than other types. A greater degree of selectivity would be evdidenced by differential learning between types of materials, while less selectivity would be evidenced by equivalent learning of stimuli regardless of the characteristics of such materials. These two dimensions will serve as the criteria by which the development of selective learning will be analyzed in the present review.

A series of studies has been conducted by Hagen and his associates investigating developmental aspects of incdental learning. The general paradigm involved extrinsic, Type 2 materials in which the central (intentional) task was rote recall of the serial position of a series of pictures stimuli presented on cards. Each of the intentional stimuli was paired with another on the same card. The incidental task was for subjects to remember the paired stimuli. Subjects were not instructed to learn thbse paired associations prior to tests of retention. Both 
central and incidental learning involved rote memory.

In an early study, Maccoby and Hagen (1965) investigated intentional and incidental learning to determine the effects of extraneous information on the selective learnint of task-relevant and task-irrelevant stimuli. Subjects were first-, third-, fifth- and seventh-grade, ethnically mixed children who had been matched on general intelligence between conditions. Stimuli were a series of picture cards with colored backgrounds. The cards were displayed in an array to the subject, and then were turned over to hide the pictures and matched colors. The intentional task was a serial position task in which subjects were asked to point to the card whose background color matched a colored chip shown by the experimenter while the front of the card was hidden from the subjects' view. The central task score was the number of times the subject correctly pointed to the cards which matched the colored chips. The incidental task consisted of identifying the picture that! had appeared with each color. The incidental retention score was the number of pictures correctly identified as being paired with background colors. In addition, a distractor was included for half the subjects which required them to listen to a tape of piano music and tap whenever a bass note was heard. This distractor was provided to increase information overload. Results indicated that central task recall increased with age. However, an interaction between age and central vs. incidental recall revealed that seventh- 
graders displayed significantly less incidental recall compared to younger subjects. Distraction affected central but not incidental recall in all grades indicating that distraction resulted in decreased intentional learning. General ability did not have a consistent nor seemingly significant role in incidental and central learning as judged by the low magnitudes of the correlations between I.Q. and retention scores, as well as variable directions of such correlations.

Hagen (1967) studied middle class children in grades one, three, five and seven. Materials in this study differed from those used in the previously described Maccoby and Hagen study (1965). Black line drawings of two objects, an animal and household object, were paired on cards with one placed above the other. Another set of cards was included in which only one object appeared on a card. Bistraction was included for half the subjects, in the same manner as in Maccoby and Hagen (1965) and for the same purpose. For the task using two objects per card, the central task was the same as in Maccoby and Hagen's study, except that subjects located the position of theobject rather than colors. The incidental task consisted of recognizing pairs of incidental" and central stimuli.

Results again indicated that central task performance increased with age and was higher in nondistraction than distraction conditions. One picture per card was significantly easier to learn at all grade levels than two pictures yper 
card, indicating that the presence of incidental stimuli distracted all subjects during central task learning regardless of age. Interestingly, distraction affected central but not incidental recall. A Grade $X$ Type of recall interaction indicated that while central recall increased with age, incidental recall did not change. Incidental recall did not decline at the seventh grade as was found in the previous study. Correlations between central and incidental recall on the two-picture task were positive through grade five, and negative at grade seven. Overall, both the results of the main analyses and correlations between incidental and central learning suggested that younger children's learning showed less differentiation between intentional and indidental simuli than older children's, perhaps attributable to either the lack of distinction between intentional and incidental stimuli by younger subjects, or their poorer intentional learning relative to older subjects.

Hagen and Sabo (1967) employing the same task as Hagen (1967) used group administration with stimuli presented in booklet format. Only the two objects per picture condition was used, however. Subjects were in grades three, five, seven and nine. Experimental manipulations included, (a) instructions to subjects in which the intentional task was to learn either positions, pairs, or boths and (b) order of report of intentional and incidental stimuli. The results indicated that while central task performance increased with age and incidental learning remained the same, the instructions 
defining the intentional task did not have the same effects for positions as for pairs. Instructions indicating that learning the positions was the intentional task did not significantly affect performance at any grade, while instructions with regard to pairs did affect performance, but only for seventh- and ninth-graders. Order of report did not affect intentional or incidental recall. The lack of effectiveness of instructions for younger subjects, and their almost equivalent performance in incidental and intentional learning indicated a lack of selectivity in the learning of younger children which was not affected by prior set. Since order of report did not affect recall, it is likely that selection of information occurred during learning rather than during the retention phase.

Druker and Hagen (1969), using the same incidental and intentional tasks as previous studies and testing children individually, investigated the effects of discriminability of the stimuli through two manipulations, (a) spatial separation of the two objects on the cards vB. contiguous position of the objects; and (b) random alternation vs. nonalternation of the positions of animals and objects. Subjects were black, working class children in grades four, six and eight. The central recall task was memory for positions, and the incidental task was memory for the pairs that appeared together. Results for central learning corroborated earlier findings in which central scores increased with grade level. None of the experimental conditions affected central recall. Results for 
incidental learning indicated that only spacing the stimuli affected recall, resulting in decreased learning scores at all ages. Thus, increasing visual discriminability through spatial separation increased selectivity to different stimulus components, resulting in a decrease of incidental learning.

Physical differentiation between intentional and incidental stimuli was also investigated by Sabo and Hagen (1973) and Wheeler and Dusek (1973). Sabo and Hagen found that recognition scores for intentional stimuli improved for all age groups: (third-, fifth- and seventh-graders) when animals and household objects were yellow and blue respectively, in contrast to a condition in which they were both black and white. Wheeler and Dusek (1973) used spatially separated vs. contiguous incidental and intentional stimuli with methodology similar to that of Druker and Hagen (1969). Results essentially replicated those found by the latter investigators and were extended to a younger sample (kindergarteners, thirdand fifth-graders). Age groups were not differentially affected by the spacing.

In summary, several trends were found in the studies reviewed above. Intentional leaming increased with age, while incidental learning either remained at a plateau or decreased with increasing age. Essentially identical results were found by Hale and Piper (1973: 1974, in press) and Schucker (1972) using similar methodology. Thus, relative to total amount of learning, the degree of incidental learning became proportionately smaller with age, suggesting that 
children's selective processes tend to center on material defined as task-relevant with increasing age. Selective processes tended to be enhanced by visual separation, a condition which decreased the amount of incidental learning at all ages. However, instructions seemed to exert relatively little influence on selective learning in younger children, and were of limited influence for older children. These results suggest that younger children may fail to distinguish between task-relevant and task-irrelevant information, despite the presence of specific instructions defining an intentional task. Therefore, they may process all information as taskrelevant. The positive correlations between incidental and intentional learning found in younger children support this interpretation. In contrast, correlations between incidental and central learning were negative for oldex children in many instances, suggesting greater selectivity in processing relevant vs. Irrelevant information.

One possible explanation for the young child's seeming inability to differentiate intentional from: incidental learning may have to do with their verbal ability. It is possible that young children lack the ability to spontaneously produce their own mediators for the coding and retention of intentional tasks causing a relative lack of differentiation between intentional and incidental stimuli. The previously mentioned study by wheeler and Dusek (1973) supports this'" possiblity., These latter investigators studied the effects of verbal labeling (overt intentional stimulus naming vs. no verbalizations) in addition to physical differentiation 
of the stimuli. It was found that subjects in:all grades who verbally labeled the central stimuli learned these more readily than subjects who did not. As in previous studies, central learning increased with grade level. Girls learned more readily than boys, apparently due to sampling factors since sex differences were, in general, not found in other studies. In contrast to the effecte of labels on central learning, subjects in the labeling condition had lower incidental learning scores than subjects in the nonlabeling condition. However, developmental trends for incidental and intentional learning were consistent with previous findings, and were not altered by labeling.

These results indicate that providng young children with a coding strategy enhanced their selective learning resulting in increased intentional and decreased incidental learning. Apparently, with the appropriate training children are capable of responding selectively. However, labeling affected all age groups to an equivalent degree and thus did not alter the basic age trends in the relationship between intentional and incidental learming obtained in previous investigations. Therefore, labeling is probably not the only factor responsible for the apparent increase in selectivity in older children. Moreover, the specific mechanisms affected by verbal training are not clear since labels may influence performanence vy affecting the subject's attention, providing a recall strategy, or both.

The effects of labeling on the intentional and incidental learning of older children are equivocal. Hagen, Meacham and 
Mesibov (1970), using the same task as earlier studies, found that labeling of intentional stimuli neither facilitated nor interfered with intentional and incidental leaming of middle class, fourth-, sixth- and eighth-graders. On the other hand, Wray (1968) found that labeling influenced the incidental learning of seventh-grade girls. Subjects who verbalized the names of incidental stimuli (the colors of geometric figures) learned more incidental-intentional pairs than subjects who did not engage in labeling activity. Intentional learning was not decreased by verbalization of incidental values. Stimulus and methodological differences between the two studies may have contributed to these discrepant findings. Wray used intrinsic stimuli, while those of Hagen et al. were extrinsic. Thus, in the former study, the subjects' attention and recall strategies may have been enhanced by both the type of atimulus employed and labeling activity. The differences between the two studies which contributed to the discrepancy are difficult to pinpoint, however, from the extant data. In comparison to the findings of Wheeler and Dusek (1973) those of Hagen et al. suggest that older children are more likely to rely on their own learning strategies, and profit less from labeling activities, than younger children for Type 2 extrinsic incidental stimuli. The studies reviewed above have revealed consistent trends in the development of selective learning using similar methodology. Yet few of them have shed any light on developmental processes which differentiate the age groups (Hagen \& Hale, 1973). Conditions which resulted in increased inten- 
tional and decreased incidental learning affected all children similarly regardless of age. Increasing perceptual discriminability of stimuli, decreasing distraction, and providing a coding strategy did not differentially influence the selective learning of children varying in age. Relative to aller children, younger children's leaming was seemingly nonselective despite efforts to isolate processes which would result in increased selectivity.

These studies, however, have limited the dimension of selectivity to the relationship between the total amount of incidental and intentional learning. While certain inferences can be made concerning selective learning processes through investiating total amoung of learning, this criterion is too narrow for the investigation of cognitive processes which may influence the development of selective learning in children. As discussed earlier, selective learning may be evident not only in subjects' total amount of learnig, but also in differential learning of various stimulus materials which may correspond to children's cognitive abilities or learning strategies. Prior studies have failed to vary this latter dimension. In all of the previous studies, the stimuli were unrelated to each other, and incidental learning necessitated rote associations for recall. None of the studies altered the type of relationship between incidental and intentional stimulus pairs, although this factor has been found to influence selective learning in adults (Quartermain \& Mangan, 1959). Thus, one could cajecture thet these studies investigated only those processes associated with the growth 
of memory for rote stimuli, and failed to examine other cognitive processes which would be expected to influence selective learning.

One characteristic of children's cognitive processes which may be expected to influence selectivity in learning is the type of representation employed by children varying in development. According to Bruner (1966), representation becomes increasingly abstract with development, proceeding from enactive to ikonic to symbolic. In partial support of Bruner's theory, Olver and Hornsby (1966) found that younger children were more likely to group pictorial stimuli on the basis of perceptual characteristics, while older children were more likely to employ conceptual characteristics. The type of representation employed by children is of utmost importance in studying selective incidental learning since recall is dependent upon information which is stored in memory. Moreover, stimuli in incidental learning studies have been typically presented pictorially in pairs, or within a complex of other stimuli, and the groupings children use to:represent stimuli may affect subsequent recall. Developmental trends in selective learning might differ: from those cited above if incidental and intentional materials were related by different forms of representation such as perceptual or conceptual (inferential). One might expect older rather than younger children to show an increase in the amount of incidental learifeg if incidental and intentional stimuli were related on a conceptual basis rather than by arbitrary assignment to be related by rote association. In studies using Hagen's 
methodology, symbolic representational abilities of older children may have enabled them to distinguish between taskrelevant and irrelevant materials more successfully than younger children by identifying the incidental stimuli as irrelevant on conceptual grounds as well as for the task at hand. Younger children may have lacked the necessary cognitive skills to distinguish between stimuli on a conceptual basis. Thus, one of the hypotheses tested in the present study was that the development of selective learning differs depending on thetype of relationship between incidental and intentional stimuli. Three types of relationships, conceptual, perceptual and nonrelated, were investigated. According to the view expressed above, selectivity should not necessarily increase with development, but should be affected by the correspondence of particular types of stimuli to developmental level. The present study assesses this possibility.

Review of Incidental Learning Studies without a Concurrent Intentional Task (Type 1)

Developmental studies of Type 1 incidental learning have been fewer in number than Type 2 studies. Despite the relative paucity of such studies, results have been consistent and contrast sharply with Type 2 studies using extrinsic incidental stimuli. Rather than finding a plateau or decrease with age, Type 1 studies demonstrate a significant increase in incidental learning up to age 12. After age 12, however, some studies have found incidental learning to continue to increase, while others have found a sudden decrease. 
Vaughan (1968) presented clustered and unclustered lists of pictures to middle class first-, fourth- and seventhgraders. Stimuli were pictures of nouns from the high frequency portion of the Lorge-Thorndike list. After predifferentiation of the stimuli in which subjects were asked to name the pictures to ensure familiarity, subjects were presented with one of the lists in one of two instructional conditions. In the incidental condition, children were told to make up sentences about each picture but were not informed of a later test of retention. In the intentional condition, subjects were instructed to perform the orienting task (creating sentences as described above) in addition to remembering the words forilater free recall. A third (comparison) group consisting only of seventh-graders was included to determine whether the orienting task would interfere with intentional recall. This group was informed of a later test of retention but not instruoted to perform the orienting task. After exposure to stimuli, subjects were allowed three minutes for free recall.

Results showed a linear increase in recall with grade, each grade being significantly different from the others. Clustered lists were recalled significantly better than nonclustered lists. While there were no differences in recall between incidental and intentional groups, the comparison group recalled a significantly greater number of words, but only for the clustered lists. Therefore, the orienting task seemed to interfere with the performance of subjects in the intentional-clustered group. 
This study supports Postman's contention that when responses are made to incidental materials through appropriate orienting tasks, incidental learning can become equivalent to intentional learning. The developmental increase in incidental learning in both clustered and nonclustered conditions, however, is not explained by Postman's analysis. The important developmental question is why learning is less selective for older children under Type 1 incidental conditions, while incidental learning in Type 2 situations does not increase with age.

The trend toward decreased selectivity with increasing age within Type 1 studies did not appear to be influenced by the provision of an orienting tasks since similar results were found in studies for which such tasks were omitted. Hale, Miller and Stevenson (1968), for instance, studied Type 1 incidental retention of filmed content in children ranging in grade from three to seven. Neither instructions nor orienting tasks were administered prior to subjects' viewing the film. Incidental learning measured by multiple choice and true-false questions increased significantly between grades three and six.

Other studies have further supported the developmental trend toward decreased selectivity with various types of procedures falling within the Type 1 rubric. Siegel and his collaborators studied incidental learning using a three choice successive discrimination task. In phase, one, the original or intentional learning task was presented without simultaneous presentation of incidental stimuli. Subjects learned to press a particular button upon presentation of 
a pictured object stimulus. After criterion was reached in original learning, each of the stimuli presented in phase one was embedded within three other objects (nine in all). The subject was still required to make the correct response to the original stimuli. No instructions were related to the subject concerning the extra stimuli. Following this phase, incidental learning was measured by presenting the previously exhibited irrelevant objects requiring the subject to respond to each stimulus by pressing the button which was correct for the original stimuli with which they had been paired. Incidental learning was defined as the association between the original learning stimuli, and the extraneous stimuli within which they had been embedded. It should be noted that this design falls more appropriately within the Type 1 rather than Type 2 rubric. Although there was an intentional task, the incidental stimuli were introduced without further instructions to subjects after original learning had reached criterion. Therefore, intentional learning was not concurrent with exposure to incidental stimuli. Siegel and Stevenson (1966) studied middle class children ranging in age between seven and fourteen, and adults. All children were above average in intellectual ability. For children, significant differences were not found between age groups on original learning, while adults learned the discrimination significantly faster than children. Incidental learning increased between ages seven and twelve, though a decrease was obtained for subjects between ages twolve and fourteen. Adulte! Incidental learning was superior to that 
of any other age group, apparently due to the ease of the tasks. Since incidental stimuli were introduced subsequent to intentional learning, subjects were more likley to have had sufficient opportunity to scan and code the incidental stimuli. In addition, the sudden presentation of irrelevant stimuli after intentional learning may have alerted subjects that these stimuli were special and should be learned. However, such explanations do not elucidate processes which may account for the developmental trend which was obtained, since they may apply to all subjects.

The decrease in Type 1 incidental learning found between ages twelve and fourteen by Hale, Miller and Stevenson (1968) and Siegel and Stevenson (1966) may have been due to the particular stimuli employed rather than a general developmental trend towards greater selectivity in those years. Though the latter interpretation is proposed by stevenson (1970), several findings support the former interpretation. First, in Siegel and Stevenson's study adults learned incidental materials more readily than any group of children. Thus, if a developmental trend towards increased selectivity with age accounted for the decrease in incidental learning between ages twelve and fourteen, then adults should have had the lowest level of incidental learning. This was clearly not the case. Second, a study conducted by Siegel and Corsini (1969) found that fourteen-year-olds' incidental recall was significantly superior to that of eight-year.; olds. when incidental stimuli were conceptually related. For unrelated stimuli, eight- and fourteen-year-olds' incidental learning was equivalent. 
Moreover, under both stimulus conditions, older subjects recognized more incidental stimuli than younger subjects. Thus, not only did the older children pay more attention to the incidental stimuli than the younger ones (demonstrated by significantly greator recognition scores) but they were also better able to use organizational properties of the materials for imporoved recall. One implication of these findings is that the decrease obtained in incidental leaming after age twelve (in some Type 1 studies) may have been due to the use of materials which were not demanding to these subjects, or did not allow for use of organized recall strategies. However, attention to stimuli did not become more selective with age. Younger children, on the other hand, were not only less likely to attend to the incidental stimuli, but were also less likely to use organizational properties of stimuli to guide recall.

The dimension of selectivity in Type 1, as in Type 2, studies has been predominantly focused upon the total amount of learning. Although Siegel and Corsini (1969) varied the nature of the relationship between the stimuli, the generality of the findings from this study is limited due to the particular methodology employed by these investigators. As noted elsewhere, the introduction of incidental stimuli subsequent to intentional learning may have itself elicited attention. It is possible that attention due to stimulus type and methodology were confounded, especially in light of the findings that recognition scores were unaffected by the experimental manipulations. Vaughan (1968) found that subjects 
of all ages recalled clustered lists better than nonclustered lists, which contradicts the findings of siegel and corsini's study in which age differences were obtained. Numerous Sthodological, stimulus and subject differences between these two studies preclude precise determination of the source of this discrepancy. Thus, developmental changes in selectivity with regard to the nature of incidental materials remain to be investigated in both Type 1 and Type 2 paradigms.

\section{Problem and Hypotheses}

To summarize, the literature suggests that Type 1 and Type 2 designs yield contradictory developmental trends of selective learning. In Type 2 situations with extrinsic incidental materials, older children seem to be more selective than younger children, showing a greater degree of differentiation between task-relevant and incidental stimuli. Incidental learming remained stable or decreased with age while concurrent intentional learning increased significantly. On the other hand, in Type 1 situations, older children appear less selective than younger children in that they exhibited better incidental learning performance than younger children. Thus, the two incidental learning paradigms suggest that both younger and older children learn eelectively, but in different situations.

These divergent trends are somewhat paradoxical. If learning is expected to become more selective with age (i.e. less global) then incidental learning should not have 
increased in Type 1 studies, and incidental learning trends found with Type 1 and 2 designs should have been similar. Apparently, the presence of a concurrent intentional task in Type 2 designs has a great deal of influence on the selectivity manifested by children. In addition, different results elicited by the two paradigms may be attributable to other sources of variation, such as the particular types of stimuli involved. The purpose of the present study was to delineate both the developmental processes and stimulus conditions which influence selective learning in children. In order to do this, Type 1 and 2 methodologies were compared. Since a direct comparison of these designs has never been conducted with children as subjects, the inclusion of both methodologies using the same materials allowed for investigation of processes affecting the divergent trends, and assessment of the relative roles of stimulus and methodological factors in earlier studies.

The present study was concerned not only with selection relating to total amount of learning, but also with selective learning of particular types of materials presumed to correspond to certain cognitive processes. As the previous review indicated, this latter dimension has received scant attention in prior studies.

One possible explanation advanced by the present author to elucidate the developmental processes involved in the seemingly divergent Type 1 and 2 incidental learning trends is that older children are more flexible in their use of selective learning strategies than younger children. According to the present author, flexibility may be considered to be 
the ability of the subject to modify learning in response to differing task demands. This criterion of flexibility is suggested by trends in the literature reviewed above. In Type 2 situations, older children seemed to be more capable of responding to intentional task instructions, and differentiating intentional and incidental stimuli than younger ones. In addition, the increase with age of Type 1 incidental learning may indicate superior ability and an increasing propensity of older subjects to learn under nonconstrained instructional conditions. This relatively nonselective approach may be advantageous since an individual. who learns more about the environment may be better prepared to interact with it than one who learns less. Differential flexibility between younger and older subjects' Type 1 and Type 2 incidental learning has neither been previously advanced as a hypothesis by other investigators nor been directly tested in previous studies of incidental learning. Flexibility has, however, been used by others to try to explain developmental differences for other cognitive processes, such as attention deploymant (e.g. Hagen \& Hale, 1973). If flexible learning is defined in the present study as the modification of learning strategy in response to implicit or explicit task demands, then learning patterns of more flexible subjects should show greater variation in response to differing; constraints relative to less flexible subjects. The comparison of Type 1 and Type 2 designs in a single gtudy allows the flexibility hypothesis to be tested. Specifically, in Type 1 and Type 2 situations, joung children are 
expected to learn similar amounts and components of the tasks despite the different task demands. Instructions, or the lack of them, would not be expected to aid younger children in differentiating task-relevant from incidental stimuli since it is hypothesized that their learning strategies would not be altered in response to instructions due to their limited representational abilities. Relative to older children, therefore, their learning would appear to be more selective in Type 1 situations and less selective in Type 2 studies. Significant differences in amount of learning between the two designs are not expected to occur for these subjects. On the other hand, older children are expected to show differentiated performance based upon the presence or absence of the intentional task. When the intentional task is present, older children are expected to be able to concentrate their efforts on that task, due to their ability to use abstract forms of representation to distinguish between stimuli. The absence of the intentional task is expected to enhance older children's incidental learning by affording them an opportunity to organize and code more stimuli than in Type 2 situations since they would not be constrained by intentional learning. Thus, Type 1 and Type 2 learning were expected to be significantly different for older subjects.

Since it was predicted that older children use flexible selective learning strategies due, in part, to differentiated representational abilities, stimuli were systematically varied to determine the extent to which discrimination of stimulus relationships would account for developmental 
differences in incidental learning. The incidental learning of younger children is expected to be less responsive to stimulus type than that of older subjects, and thus less flexible. Subjects with limited representational skills would not be expected to differentially learn stimuli which vary in the type of concept represented due to the decreased likelihood that they would be able to discriminate these stimulus relationships. Older children's learning of particular materials would be expected to show differentiation between stimulus types relative to their representational capabilities. Greater flexibility would be evidenced by greater variation for older subjects' learning of stimuli differing in type.

In the present study, therefore, for both Type 1 and Type 2 conditions, pairs of stimuli were presented which possessed one of three relationships (i.e. inferential conceptual, perceptual, or unrelated) in order to test the hypothesis that the incidental learning of older children is influenced by differentiated representational abilities to a greater degree than that of younger children. Predictions were that older children's incidental learning would be greatest for conceptual groupings, followed by perceptual groups, and least for stimuli with no relationships. Younger children's performance was expected to be similar across all three stimulus types, since it was expected that they would use the same learning strategy regardless of the organizational properties of the stimuli. However, though not predicted, it was also possible that incidental learning 
in the perceptual condition would be greater than in the conceptual or unrelated conditions, based upon olver and Hornsby's (1966) findings that young children are more likely to relate stimuli on perceptual rather than conceptual characteristics (in their picture task).

In summary, the variables investigated in the present study were: (a) task demands (comparison of Type 1 and Type 2 methodology), (b) type of representation of incidental and intentional stimulis and (c) developmental level.

Based upon the preceding rationale, the following hypotheses were tested, (a) older children would be more responsive to different task demands (Type 1 vs. Type 2) than younger children. Thus, older children were expected to show a significant difference in retention between Type 1 and Type 2 methodologies, while the performance of younger children was expected to be equivalent for both types of task presentation. For example, identical stimulus pairs are presented in Type 1 and Type 2 conditions. The initial instruction for the former condition informs: the child that he or she is to look at the stimuli, while the instruction for the latter condition directs the child to remember one member of each stimulus pair. The hypothesis of flexibility for older, and nonflexibility of younger children would be supported if older subjects learned a significantly greater amount of these latter stimuli in the Type 2 conditions compared to Type 1 conditions, while younger subjects evidenced equivalent learning of these stimuli in Type 1 and Type 2 conditions. These patterns should be obtained regardless 
of possible different levels of learning between younger and older subjects. Support of this hypothesis would be obtained if analysis of variance yłolded a significant Grade X Type of task presentation interaction in the direction specified above. (b) Type of representation of the stimuli (conceptual, perceptual, or unrelated) would influence the retention of older children to a greater degree than that of younger children. The relationship between stimulus type and the cognitive abilities of children varying in developmental level was expected to affect retention. Thus, younger children are expected to show equivalent amounts of retention regardless of the organization of the stimuli, while older children's performance is expected to be greatest when stimuli were related by an inferential category, least when stimuli were unrelated, and intermediate when stimuli embodied perceptual relationships. For example, since stimuli are presented as pairs, measures of pair retention should evidence different patterns of retention for older and younger subjects. The hypothesis of flexibility of older subjects would be supported if their pattern of pair retention was significantly differentiated by stimulus relationship. Nonflexibility of younger subjects would be evidenced by a nondifferentiated pattern of pair retention regardless of stimulus type. A significant Grade X Stimulus representation interaction should be obtained from the analysis of variance to support the hypothesis. 


\section{CHAPTER II}

\section{METHOD}

\section{Design}

A three-way factorial design was employed. The three factors were: (a) type of task presentation (Type 1 and Type 2): (b) type of relationship between stimulus pairs (inferential, perceptual, and unrelated), and (c) developmental level (first- and sixth-grade subjects). There were 12 experimental groups. Though sex was not an experimental variable, it was included as a factor in statistical analyses.

\section{Subjects}

Subjects were 168, white, middle class first- and sixthgrade children attending an elementary school in a suburban community outside New York City. An equal number of children (84) at both grade levels participated in the study. The children were average to above average in I.Q. and achievement as described by school administrators. Although individual I.Q. scores were not made available to the author for sixthgraders, and first-graders had never been administered an I.Q. test, the group data for sixth-graders revealed that the mean Lorge-Thorndike I.Q. was 112.

Seven boys and seven girls were randomly assigned to each of the 12 experimental conditions. Children from each class were represented in all conditions through random 
assignment. The mean age of the first-graders was 6.87 years, while the standard deviation was .31 years. The mean and standard deviation of sixth-graders' age was 11.87 and .34 years respectively. Color blind children were excluded from the sample as color was one of the stimulus attributes in the perceptual stimulus condition. For sixth-graders, school health records were used to identify color blind children. Seven boys were exāluded due to color blindness. First-grade children were asked to name the stimulus colors after all experimental procedures had been concluded, as they had not been tested for color blindness by the school nurse. None of the first-grade children were eliminated on the basis on this criterion.

\section{Stimuli}

Eight pairs of stimuli were utilized for each stimulus condition. The same 16 stimuli were used for all conditions, but were paired differently within each condition in order to comply with the criteria for conceptual, perceptual and unrelated pairs. By using one set of stimuli for all three conditions, intercondition factors such as stimulus difficulty, codability, brightness, size, shape, etc. were controlled to avoid the confounding of these irrelevant variables with stimulus representation.

Each stimulus was a colored drawing of a common object. All pictures were drawn within a 5.1 by 5.1 centimeter area centered on a 7.6 centimeter white square. The original outlined drawings were xeroxed so that all replications would be identical. Stimuli were colored with pencils and pens, 
and were identical for all conditions. Each pair of pictures was centered on a separate sheet of white, standard size typing paper ( $21.5 \times 27.9$ centimeters) with one picture placed directly above the other. The eight stimuli which were identified as intentional stimuli in the Type 2 condition were always the top member of a pair regardless of stimulus and instructional condition. In addition, the eight intentional and eight incidental stimuli were the same for all conditions to control for intentional task difficulty between conditions. Intentional stimuli were, flower, tent, car, fruit, lamp, shoes, bee and face. Incidental stimuli were, tree, house, boat, egg, sun shirt, kite and hand. Twenty-four different stimulus pairs were thus created by pairing the eight top and eight bottom stimuli differently within each condition.

After each of the 24 pairs of stimuli had been mounted on a sheet of paper, it was placed in a clear plastic protective page. Stimulus sets of eight pairs each were then placed in separate, flexible covered looseleaf binders which were used for presentation to the subjects. Criteria for Construction of Stimulus Pairs

Since the relationship within stimulus pairs was to be based upon Bruner's theory of the development of representation, it was necessary to avoid forming pairs whose members were associatively related. Thus, the first step in creating appropriate stimuli was to choose pairs whose membersithad an infrequent or zero degree of associative relatedness. This was accomplished by referring to children's word associa- 
tion norms developed by Entwisle (1966) and Palermo and Jenkins (1964). Extensive description of stimulus selection procedures appears in the Appendix.

The second major criterion used to develop the stimuli concerned the type of representation by whichintrapair stimuli within experimental condition were related. Criteria specified by Olver and Hornsby (1966) for types of equivalence which were consistent with Bruner's theory of the development of representation were used to develop conceptually and perceptually related pairs. Stimulus Representation Conditions

Conceptually related pairs. Intrapair stimuli were related by an inferential concept, and had no. perceptual feature in common. Thus, the type of relationship within pairs was based upon abstract, or symbolic, rather than phenomenal equivalence. Intrapair conceptual and perceptual categories did not overlap within or between conditions. Each pair was an instance of a different category. Conceptual pairs were, flower-tree, tent-house, car-boat, fruit-egg, lamp-sun, shoes-shirt, bee-kite, and face-hand.

Perceptually related pairs. Intrapair stimuli were related perceptualiy, but not conceptually. of the eight pairs, five were related by color, two by shape, and one by pattern. Each of the pairs represented a different perceptual value. Perceptual pairs were tent-hand (brown), flower-kite (red), shoes-house (blue), car-tree (green), lamp-boat (purple), fruit-sun (round), face-egg (oval), and bee-shirt (striped). 
Unrelated pairs. Pairs in this condition were defined as sharing neither a conceptually nor perceptually equivalent relationship. An effort was made to pair stimuli which shared no type of meaningful relationship. Characteristics of children's word associations described in Appendix A were thus considered. Unrelated pairs were, flower-boat, tent-sun, shoes-hand, car-egg, lamp-tree, fruit-shirt, bee-house and face-kite.

\section{Type of Task Presentation}

\section{Type 1}

Subjects were instructed to look at each pair of stimuli one at a time, but were not informed of later retention tasks. Each pair was exposed for 10 seconds as measured by a stopwatch. Pairs were presented in random order to each subject to control for the confounding of order with experimental condition. A table of random numbers was used to generate a different random order for each subject. Subsequent to exposure, all subjects were administered free recall and matching of pairs retention tasks.

\section{Type 2}

Stimuli were presented with the same experimental constraints described above for the Type 1 instruction. Type 2 differed from Type 1 only in the initial instruction administered by the experimenter. Subjects were instructed to look at both the top and bottom members of each of the pairs, but to remember only the top picture since he or she would be asked for later retention of those stimuli. The top pictures were thus the intentional stimuli, while the bottom were the inci- 
dental stimuli. The top stimulus was designated as intentional to avoid confusion which may have been caused by switching from top to bottom on each successive page. Subsequent to exposure, subjects were asked to recall all of the stimuli they could, including the bottom ones. The matching of pairs task was also administered.

\section{Retention Tasks}

Free Recal1

Immediately following exposure to stimuli, subjects in all conditions were asked to recall as many of the pictures as they could in any order. This task was not timed, and all subjects indicated when they had finished. The experimenter recorded subjects' responses verbatim by hand. Matching of Pairs

Subsequent to free recall, subjects were asked to match the top and bottom stimuli which had been seen together during initial exposure. This task was presented in the following manner. Each of the pictures appearing on top was presented individually. They had been mounted in the center of half of a piece of standard size typing paper (13.9 X 21.5 centimeters) and protected in plastic. Presented simultaneously with a stimulus were all eight pictures which had appeared on the bottom. These pictures were arranged on two looseleaf pages so that four stimuli were centered on one page, and four were arranged in the same manner on the next page. The pages were opened so that all eight pictures were viewed simultaneously. After the child made a choice, another picture which had appeared on top was presented, while the 
preceding one was removed. The looseleaf pages were also turned to reveal the eight bottom stimuli whose positions had been rearranged. This procedure was used to ensure that position cues during the matching task would not influence performance. Using a table of random numbers, eight orders for the physical arrangement of the bottom stimazi were generated. In addition, by presenting the same bottom stimuli on all trials, replacement of stimuli was ensured so that probabilities for guessing were not altered. Orders for presenting the top and bottom stimuli were randomized for each subject. The experimenter recorded subjects' choices by hand.

Free recall preceded matching of pairs in all cases to minimize the possibility that one task would influence the other.

\section{r.s.}

Procedure

Each subject was seen individually by the experimenter in a small room. When the subject entered the room, the experimenter asked the subject to sit opposite her at a table. The experimenter then recorded the subject's name, sex and birthday. In order to determine that each subject knew top from bottom, he or she was shown a pair of boxes which had been drawn in ink on an index card, and was asked to point to the top and bottom boxes. Only two first-grade boys could not locate top and bottom, and could not be corrected. Therefore, they were eliminated from the study. The experimenter then told the subject that she had some pictures that 
she wanted to show to the subject. The appropriate looseleaf binder was then presented, but the subject-was not yet allowed to open it. The experimenter explained that on each page there were two pictures, one of which was on top of the other. In Type 1 conditions, subjects were told only to look at the pictures. In Type 2 conditions, the following instruction for intentional learning of the top stimilua was included, "Look at both pictures, and remember the one that is on top on each page because I will ask you to remember those pictures when you're finished looking at all of them." The subject was then told to turn each page only when the experimenter said "turn". The experimenter asked the subject if he or she had any questions, and told the subject to begin. When the subject turned to the first page, the experimenter began the stopwatch. After 10 seconds, the subject was directed to turn the page, and the stopwatch was stopped until the next page was fully exposed. This procedure was followed for each of the pairs. When the child had finished looking at all eight pairs, the looseleaf book was removed and the free recall and matching of pairs tasks were administered. After completing the latter task, the subject was asked to identify the stimulus colors. At the completion of all procedures, the subject was asked if he or she had any questions. The experimenter also asked the subject to promise not to tell other children in his or her class, or in other classes, about their activities while being with the experimenter. All children felt this was reasonable, and agreed to tell none of the others. 
Immediately after one child left the room, and before the next subject arrived, the order of stimuli was changed according to random permutation.

The experimental procedures were easily understood by all subjects. None of the children were eliminated from the study on the basis of being unable to follow directions or complete the experimental procedure. Total time of all procedures was about 15 minutes.

\section{Dependent Measures}

Several dependent measures were analyzed. The following measures were derived from the free recall task.

Total number of stimuli recalled (FRTOTAL). The number of stimuli which were correctly recalled was totaled. Repetitions or errors were excluded.

Total number of intentional stimuli recalled (FRINT).

This measure consisted of the total number of correctly recalled intentional (top) stimuli.

Total number of incidental stimuli recalled (FRINC). The total number of correctly recalled incidental (bottom) stimuli was counted.

Proportion of intentional to total stimuli recalled (FRPRINT). A ratio of intentional to total recall was calculated for each subject to determine whether this proportion would $\therefore$.? differibetween groups. This information differed from FRTOTAL, FRINT, and FRINC since amount of recall may differ between grades and experimental coriditions, but relative proportions could remain unaffected. 
Number of conceptual, perceptual or unrelated pairs (FRCONPR, FRPERPR, and FRROTEPR respectively). Since stimuli between conditions were the same despite different pairings, it was of interest to determine whether the blocking of pairs affected the manner in which stimuli were recalled, and/or whether implicit nonblocked relationships also affected recall organization. Pairs of stimuli which were recalled contiguously as conceptual, perceptual or unrelated pairs were totaled for each subject in all expermental conditions. Thus, the occurrence of conceptual, perceptual and unrelated pairs within their appropriate conditions could be compared with such occurrences across stimulus conditions.

Number of within treatment pairs (FRTRPR). Only those pairs designated as conceptual in the conceptual condition, perceptual in the perceptual condition, and unrelated in the unrelated condition were totaled for each subject.

Latency to respond (FRLAT). The time interval beginning with the end of the experimenter's instruction for free recall, and ending with the subjects' first response was measured with a stopwatch in fifths of seconds.

The matching of pairs task yielded the following measure. Total number of correctly matched pairs (PRTOTAL). Those pairs which had been designated as conceptual within a conceptual condition, perceptual within a perceptual condition, and unrelated within an unrelated condition were totaled.

Pretests

To determine whether each stimulus was recognizable and 
nameable by the younger children, 12 first-grade children ( 6 boys and 6 girls) were pretested. Each child was seen individually, and asked to name all of the stimuli. Results showed that all stimuli were easily recognized and labeled correctly.

Pretesting was also conducted to determine whether the conceptual, perceptual and unrelated pairs conveyed the intended relationships to the subjects. Since it was hypothesized that only sixth-graders would be differentially affected by stimulus type, 17 sixth-graders (10 boys and 7 girls) were pretested. Each pretest subject was seen individually and asked to tell how pairs of stimuli were alike. Responses were scored as conceptual, perceptual, not alike, or other. All conceptual pairs were identified as conceptually related by every subject. For perceptual pairs, in no instance were pairs identified as conceptually related. In some scattered instances, subjects responded that pairs were not alike, or provided relational responses (for example, the sun makes an orange grow). Chi square analysis corrected for continuity indicated that these scattered responses did not differ from chance. Therefore, perceptually related stimuli were seen as such by subjects. For unrelated stimuli, the majority of responses indicated that pairs were not alike. Scattered responses were in the other category. Chi square analyses corrected for continuity indicated that these responses did not differ from chance. The pretest data indicated that stimuli were valid with respect to the criteria by which they had developed, and that stimulus conditions were differentiated according to the dimensions defined above. 
CHAPTER III

RESULTS

Each dependent measure was analyzed with a $2 \times 2 \times 3 \times 2$ (Grade X Type of task presentation X Stimulus representation $X$ Sex) fixed factor analysis of variance. The results of the analyses for each measure will be presented separately with explication of their elucidation of both of the advanced hypotheses. The two predictions were: (a) sixth-graders' retention under Type 1 and Type 2 conditions would be significantly different while retention of first-graders would not be significantly different under both instructional conditions; and (b) sixth-graders' retention under varying stimulus conditions would be significantly different, while that of firstgraders would be equivalent and would not differ significantly. Evidence to confirm the hypotheses would have been obtained if each of two, two-factor interactions resulted from the analyses. These were Grade $\mathrm{X}$ Type of task presentation and Grade X Stimulus representation interactions.

The four factors will henceforth be referred to as grade, type, stimulus and sex for grade, type of task presentation, stimulus representation and sex respectively. Means and standard deviations for all dependent measures grouped by grade, type and stimulus are presented in Tables $A$ through $\mathrm{J}$ in the Appendix. Table $\mathrm{K}$ presents a summary of $\mathrm{F}$ ratios obtained in the anlyses of the dependent variables. 
Total Number of Stimuli Recalled

The analysis of variance yielded a signficant main effect for grade $(\underline{F}=147.03, \mathrm{df}=1 / 144, \mathrm{p}(001)$. No other main effects were significant. Sixth-graders recalled significantly more atimuli than first-graders.

The predicted Grade X Type interaction was significant $(F=12.75, \underline{d f}=1 / 144, \underline{p}(.001)$. However, analysis of simple main effects showed that sixth-graders' retention was not significantly different under either type of task presentation. while first-graders recalled more stimuli in the Type 2 compared to the Type 1 condition. Table 1 presents the means of first- and sixth-graders' total recall for Type 1 and 2 conditions. The interaction is presented in Figure 1. Thus, the hypothesis that sixth-graders' retention would be significantly different under different instructional conditions, while that of first-graders would be equivalent was not supported, and, in fact, the opposite was found.

The Grade $\mathrm{X}$ Stimulus interaction was not significant $(\mathrm{F}=1.64, \mathrm{~d} f=2 / 144, \mathrm{p}=.19)$. Neither first- nor sixth-graders' total recall was significantly differentiated by stimulus representation.

Additional findings were significant Type X Stimulus $(\underline{F}=3.19, \mathrm{~d} f=2 / 144, \underline{p}=.045)$ and $\operatorname{Sex} X$ Grade $(\underline{F}=4.19, \mathrm{~d} f=1 / 144$, $\mathrm{p}=.041$ ) interactions. Analysis of simple main effects of the former interaction indicated that retention was significantly higher in the Type 2-conceptual condition compared to the Type 1-conceptual group. Total recall in the Type 2-perceptual condition was almost significantly greater than in the Type 1- 
TABLE 1

Means for Total Number of Stimuli Recalled

Grouped by Grade and Type

\begin{tabular}{c|c|c}
\hline Grade & Type 1 & Type 2 \\
\hline 1 & 4.92 & 6.28 \\
\hline 6 & 9.16 & 8.59 \\
\hline
\end{tabular}




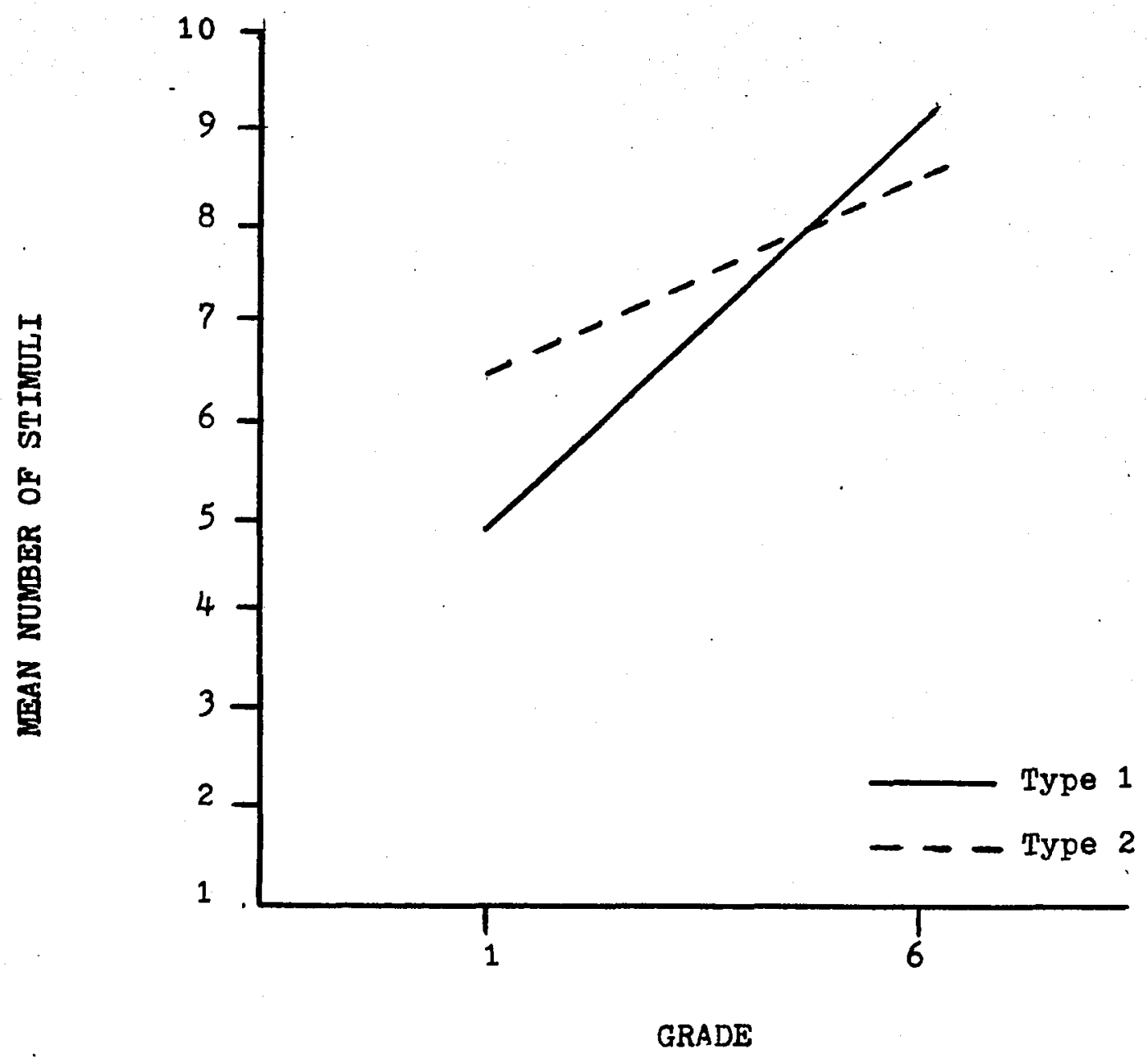

Figure 1. Grade X Type interaction for number of stimuli recalled. 
perceptual condition $(.10<\mathrm{p}>.05)$. Total recall in Type 1- and Type 2-unrelated conditions were not significantly different. Total amount of recall seemed to be enhanced in Type 2 vs. Type 1 caditions only for the conceptual group. Simple main effects of the significant Sex $X$ Grade interaction indicated that while there was no significant differences between boys and girls in the first-grade, sixth-grade girls recalled significantly more than sixth-grade boys. Total Number of Intentional (Top) Stimuli Recalled

In order to determine whether the type of task instruction affected sel zction of specific task information for recall within total recall, and if this occurred differentially for children of different grades and under different stimulus conditions, the aforementioned four-factor analysis of variance was conducted on this measure. Significant main effects were obtained for type $(\underline{F}=103.80, \underline{d f}=1 / 144, \underline{p}<.001)$ and for grade $(\underline{F}=89.42, \underline{d f}=1 / 144, p<.001)$. Recall of intentional stimuli was significantly greater in Type 2 relative to Type 1 conditions. Sixth-graders recalled significantly more intentional stimuli than first-graders.

Neither the Grade $X$ Type $(\underline{F}=.03, \mathrm{~d} f=1 / 144, p>.50)$ nor the Grade $X$ Stimulus ( $\underline{F}=1.47, \underline{d f}=2 / 144, \underline{p}=.23$ ) interactions were significant. In addition, no other interactions were significant.

These results indicated that both first- and sixthgraders learned more intentional stimuli under Type 2 instructional conditions, although sixth-graders recalled more than first-graders. Stimulus type did not affect 
intentional recall for subjects of either age level. Total Number of Incidental (Bottom) Stimuli Recalled

The analysis of variance conducted on this measure revealed significant main effects for type $(\underline{F}=78.64, \underline{d} f=1 / 144$, $\mathrm{p}<.001)$ and grade $(\underline{F}=63.06, \underline{d f}=1 / 144, \underline{p}<.001)$. More incidental stimuli were recalled in Type 1 than in Type 2 conditions, and sixth-graders recalled more stimuli than first-graders.

The Grade X Type interaction was significant $(\underline{F}=30.90$, $\mathrm{d} f=1 / 144, \mathrm{p}<.001)$. Means for total amount of incidental stimuli grouped by grade and type are presented in Table 2. The Grade $X$ Type interaction is presented in Figure 2. Analysis of simple main effects revealed that both first- and sixthgraders recalled significantly more incidental stimuli in Type 1 vs. Type 2 conditions. However, sixth-graders' incidental recall was enhanced by Type 1 instructions to a greater degree than first-graders'. While sixth-graders' incidental recall was superior to first-graders' for both Types, this difference was significant only in the Type 1 condition. These finding provide partial support for the hypothesis that sixth-graders' recall would be affected by task instructions to a significantly greater degree than that of first-graders.

The Grade X Stimulus interaction was not significant $(\underline{F}=.48, \underline{d f}-2 / 144, \underline{p}>.50)$. Contrary to expectation, stimulus type influenced neither the total number of incidental stimuli recalled, nor did this factor interact with grade.

Two additional interactions were significant. The Sex $\mathrm{X}$ 
TABLE 2

Mean Number of Incidental Stimuli Recalled Grouped by Grade and Type

\begin{tabular}{c|c|c}
\hline Grade & Type 1 & Type 2 \\
\hline 1 & 2.26 & 1.66 \\
\hline 6 & 4.69 & 2.09 \\
\hline
\end{tabular}




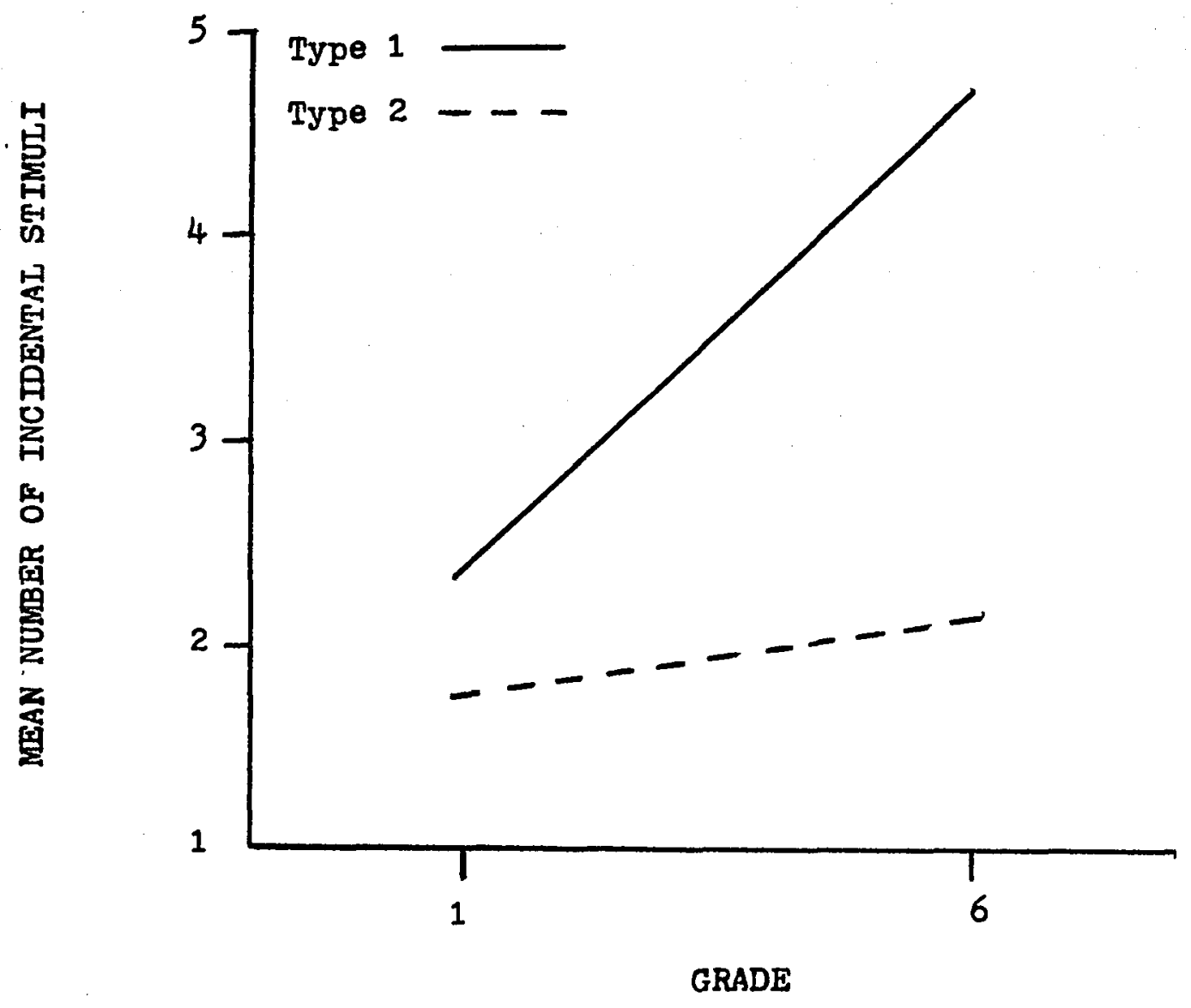

Figure 2. Grade X Type interaction for the number of incidental stimuli recalled. 
Grade $(E=10.09, d f=1 / 144, p=.002)$ and Sex $X$ Grade $X$ Stimulus $(\underline{F}=3.82, \underline{d f}=2 / 144, \underline{p}=.02)$ interactions revealed that firstgrade boys' and girls' incidental recall was not significantly different under any stimulus condition, while sixth-grade girls' recall was significantly greater than sixth-grade boys' but only in the perceptual and unrelated stimulus conditions. Means for total incidental recall grouped by sex, grade and stimulus are presented in Table 3. The interaction is depicted in Figure 3. The hypothesis that sixth-grade subjects' retention would be differentially affected by stimulus representation, while that of first-graders would not be influenced in this manner, was partially supported by the latter threefactor interaction. While stimulus type did not differentially affect the number of incidental stimuli recalled by firstgrade boys or girls, and sixth-grade boys, Tukey tests for pairwise comparisons of sixth-grade girls' recall revealed significant differences in recall between the stimulus groups. Incidental recall for older girls was equivalent in the perceptual and unrelated conditions, while subjects in these conditions recalled significantly more than subjects in the conceptual condition. Though these findings lend partial support to the hypothesis, it was expected that recall in conceptual conditions would be superior to recall in both the perceptual and unrelated conditions which was clearly not obtained.

An additional finding of the Sex $X$ Grade $X$ Stimulus interaction was that despite superior recall by sixth-graders in all conditions, first- and sixth-grade boys' recall in the 


\section{TABLE 3}

Mean Number of Incidental Stimuli Recalled

Grouped by Grade, Sex and Stimulus

\begin{tabular}{l|c|c|c|c}
\hline \multirow{2}{*}{ Stimulus } & \multicolumn{2}{|c|}{ Grade 1 } & \multicolumn{2}{c}{ Grade 6 } \\
\cline { 2 - 5 } & Female & Male & Female & Male \\
\hline Conceptual & 1.76 & 2.07 & 3.00 & 3.50 \\
\hline Perceptual & 1.71 & 2.42 & 4.07 & 2.64 \\
\hline Unrelated & 1.71 & 2.07 & 4.14 & 3.00 \\
\hline
\end{tabular}




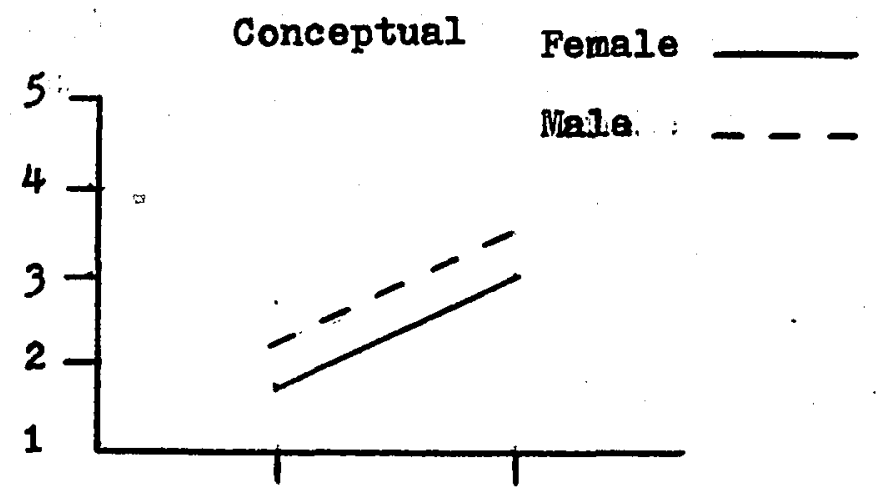

年
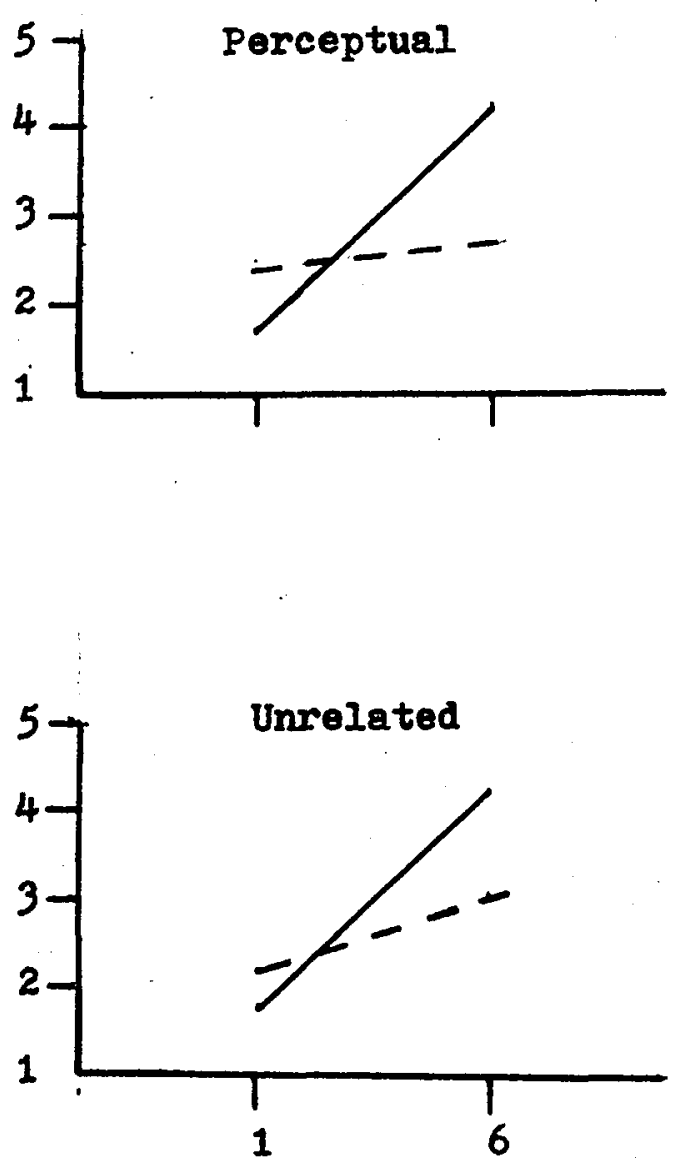

GRADE

Figure 3. Sex X Grade X Stimulus interaction for the number of incidental stimuli recalled. 
perceptual condition was not significantly different. Proportion of Intentional to Total Stimuli Recalled

Since the data for this analysis were proportional, the analysis of variance was conducted on the arcsin transformation of these scores as recommended by Winer (1971, pp. 399-400). A significant main effect for type was obtained ( $F=72.77$, $\mathrm{d} f=1 / 144, p<.001)$ which ind icated that the proportion of intentional to total stimuli recalled was greater in Type 2 than in Type 1 conditions. Of great importance was the finding that the main effect for grade was not significant ( $F=.62$, $\mathrm{d} f=1 / 144, p=.43$ ) which indicated that the degree of selective recall of intentional stimuli was the same for subjects of both grade levels under both instructional conditions. Sex and stimulus main effects were not significant.

Neither the Grade X Type ( $\underline{F}=2.34, d f=1 / 144, p=.12)$ nor the Grade $X$ Stimulus $(\underline{F}=.77, \underline{d f}=2 / 144, \underline{p}=.46)$ interactions were significant. Thus, neither hypothesis was supported by the analysis of this measure. Only the Sex X Grade interaction was significant $(\underline{F}=4.07, \underline{d f}=1 / 144, \underline{p}=.04)$. Analysis of simple main effects revealed that the proportions of firstand sixth-grade boys was not significantly different, while first-grade girls had a higher proportion of intentional to total stimuli than sixth-grade females. This finding seems to be concordant with those discussed earlier concerning sixth-grade girls' superior incidental recall relative to that of all other groups. Superior incidental recall. would therefore reduce the proportion of intentional to total recall. 
Total Number of Correctly Matched Pairs

This measure is analogous to the measure of incidental learning used in studies which employed Hagen's Type 2 methodology. Thus, it is of utmost significance since it provides a direct basis of comparison with prior research.

The analysis of variance of this measure revealed significant main effects for grade $(\underline{F}=9.00, \underline{d f}=1 / 144, \underline{p}=.004)$, type $(\underline{F}=50.49, \mathrm{~d} f=1 / 144, \mathrm{p}<.001)$ and stimulus $(\underline{F}=30.48, \mathrm{~d} f=$ 2/144, $\mathrm{p}<.001$ ). Sixth-graders matched a significantly greater number of pairs correctly than first-graders in both Type 1 and 2 conditions. For both first- and sixthgraders, more pairs were matched correctly in Type 1 vs. Type 2 conditions. For the stimulus main effect, Tukey pairwise comparisons of marginal means revealed that all stimulus conditions were significantly different from each other. Significantly more pairs were matched correctly by subjects in the perceptual condition compared with both the conceptual and unrelated conditions ( $p<.01$ for both comparisons), and significantly more pairs were correctly matched by subjects in conceptual compared to those in the unrelated condition.

The lack of significance of either the Grade X. Type $(\underline{F}=.89, d f=1 / 144, \underline{p}=.34)$ or the Grade $X$ Stimulus $(\underline{F}=.25$, $\mathrm{df}=2 / 144, \mathrm{p}>.50$ ) interactions indicated that trends for matchIng of stimulus pairs were the same for subjects in both grades. Thus, neither hypothesis was supported. Means for the total number of correctly matched pairs grouped by grade, type and stimulus are presented in Table 4. 
Figure 4 depicts the trends cited above. It can be seen that the smallest differences between first- and sixth-graders occurred in the Type 2-unrelated condition, which is the particular group that corresponds to Hagen's methodology, and the Type 2-perceptual condition. In addition, although a significant interaction was not obtained, it appears that the Type 2-conceptual condition affected older subjects' retention to a greater extent than firstgraders'. These findings indicate that incidental learning in Type 2 situations can increase with age, especially when meaningful stimuli are presented, and certainly supplement trends found by investigators using unrelated pairs as stimuli. Number of Conceptual Pairs Recalled

The analysis of variance revealed significant main erfects for grade $(\underline{F}=4.24, \underline{d f}=1.144, \underline{p}=.04)$, type $(\underline{F}=26.50$, $\underline{d f}=1 / 144, \underline{p}<.001)$ and stimulus $(\underline{F}=35.69, \underline{d f}=2 / 144, \underline{p}<.001)$. Sixth-grade subjects recalled significantly more conceptual pairs than first-graders, and more conceptual pairs were recalled in Type 1 compared to Type 2 conditions. For the stimulus factor, Tukey tests for pairwise comparisons of marginal means revealed that conceptual pairs in the conceptual condition were recalled to a significantly greater degree than conceptual pairs in the perceptual $(p<.01)$ and in the unrelated conditions $(p<.01)$ while the latter two conditions did not differ significantly from each other. These findings demonstrate that blocking conceptual pairs produced superior conceptual pair recall compared to the mere presence of conceptual pairs in the other stimulus 
TABLE 4

Mean Number of Correctly Matched Pairs Grouped by Grade, Type and Stimulus

\begin{tabular}{l|c|c|c|c}
\hline \multirow{2}{*}{ Stimulus } & \multicolumn{2}{|c|}{ Type 1 } & \multicolumn{2}{c}{ Type 2 } \\
\cline { 2 - 5 } & Grade 1 & Grade 6 & Grade 1 & Grade 6 \\
\cline { 2 - 5 } Conceptual & 4.71 & 5.42 & 2.92 & 4.21 \\
\hline Perceptual & 6.35 & 7.35 & 3.85 & 4.07 \\
\hline Unrelated & 2.64 & 4.50 & 1.35 & 1.71 \\
\hline
\end{tabular}




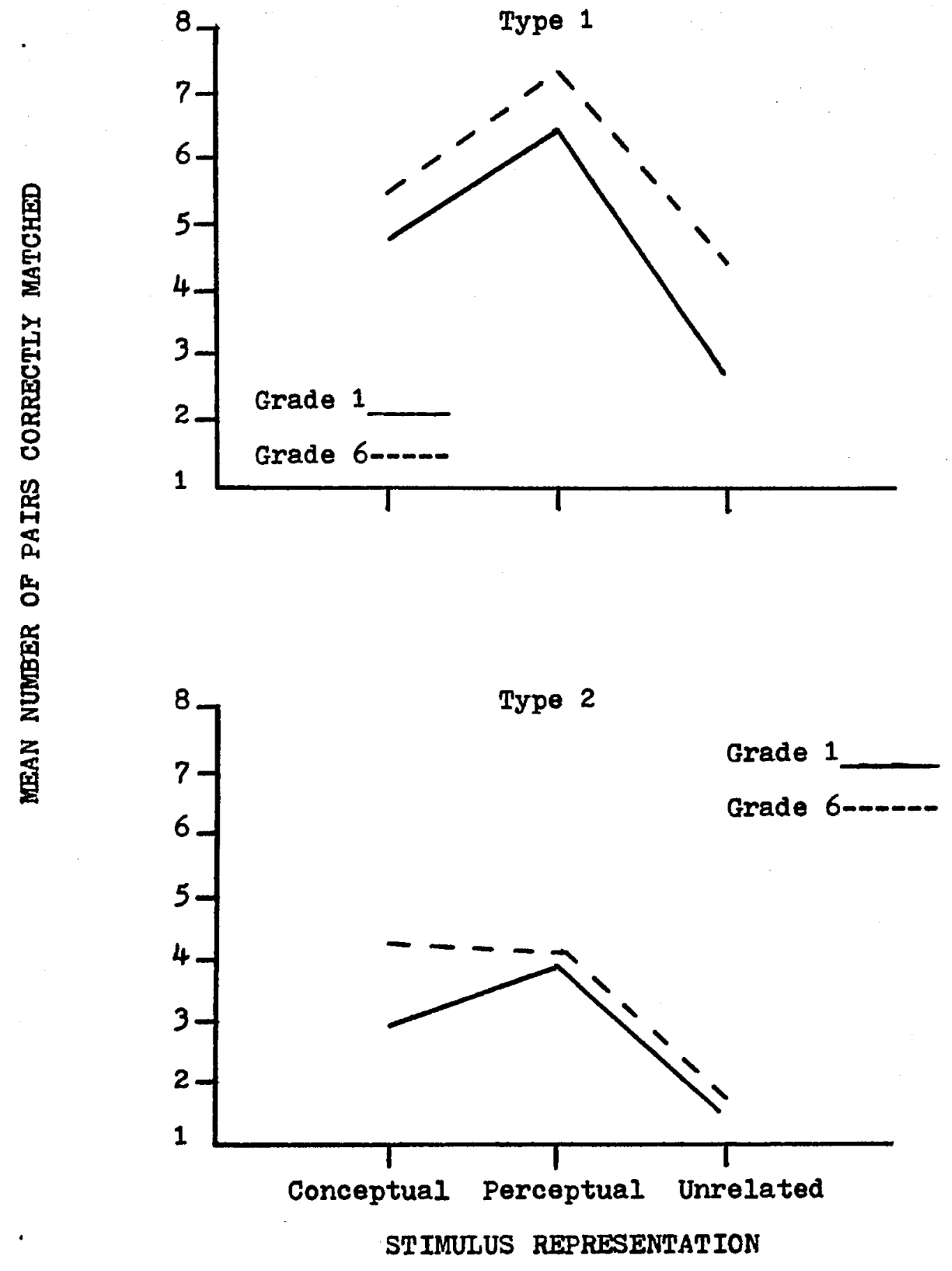

Figure 4. Main effects for grade, type and stimulus : Total number of correctly matched pairs. 
conditions. Thus, the experimental treatment was effective in producing subjects' apprehension and recall of the intended stimulus relation in the appropriate condition.

The Type X Stimulus interaction was significant ( $F=15.33$, $\underline{d f}=2 / 144, \underline{p}(.001)$ revealing that only for Type 1 conditions was recall of conceptual pairs in the conceptual condition significantly superior to such recall in the perceptual and unrelated conditions ( $\underline{p}<.01)$. Conceptual pair recall in the latter two conditions were not significantly different. The interaction further revealed that recall of conceptual pairs was significantly superior in Type 1 compared to Type 2 groups only in the conceptual condition. Means for the recall of conceptual pairs grouped by type and stimulus are presented in Table 5.

Neither the Grade $X$ Type $(F=2.07, d f=1 / 144, p=.15)$ nor the Grade X Stimulus ( $p=1.28, \alpha f=2 / 144, p=.28)$ interactions were significant, revealing no differences in the pattern of conceptual pair recall between first- and sixth-graders.

Sex was not significant either as a main effect, or in interaction with other variables. Number of Perceptual Pairs Recalled

The analysis of variance for this measure revealed significant main effects for grade ( $F=8.25, \underline{d f}=1 / 144, \underline{p}=.005)$, type $(\underline{F}=22.93, \underline{d f}=1 / 144, p<.001)$ and stimulus $(\underline{F}=39.36$, $\mathrm{d} f=2 / 144, \mathrm{p}(.001)$. Recall of perceptual pairs was significantly greater for sixth-graders and for subjects in Type 1 rather than Type 2 conditions. Tukey tests of pairwise comparisons of marginal means for the significant stimulus 


\section{TABLE 5}

Mean Number of Conceptual Pairs Recalled

Grouped by Type and Stimulus

\begin{tabular}{l|c|c}
\hline \hline Stimulus & Type 1 & Type 2 \\
\hline Conceptual & 1.96 & .46 \\
\hline Perceptual & .25 & .07 \\
\hline Unrelated & .25 & .14 \\
\hline
\end{tabular}


factor revealed that recall of perceptual pairs in the perceptual condition was significantly greater than in either the conceptual or unrelated conditions ( $p<.01$ for both comparisons). while the latter two conditions did not differ from each other. The blockingoff perceptaal pairs. therefore, significantly influenced such recall.

The Type $X$ Stimulus interaction was significant $(E=12.39$. df $=2 / 144, \mathrm{p}<.001)$. Means for the total number of perceptual pairs recalled grouped by type and stimulus are presented in Table 6. This interaction revealed that recall of perceptual pairs in Type 1 conditions was significantly greater than in Type 2 conditions, but only in the perceptual and unrelated stimulus conditions. Further, for Type 1, recall of perceptaal pairs in the perceptual condition was significantly greater then in both the conceptuil and unrelated conditions ( $\mathrm{p}<.01$ for both comparisons) while the latter two conditions did not differ significantly. For Type 2 conditions, recall in the perceptaal condition was ofgnificantly greater than in the unrelated condition ( $2<.01$ ) while no other comparisone were significant. In general, the Type 1 perceptanl condition facilitated recall of perceptual pairs to a greater extent than all other conditions, while Type 2 instructions depresed such recall.

With regard to the hypotheses, a sigmificant Grade X Type interaction was obtained ( $\mathrm{F}=8.25, \mathrm{df}=1 / 144, \mathrm{p}=.005)$. but the Grade $X$ Stimulus interaction was not significant (Fi=1.73, $\mathrm{df}=2 / 144, \mathrm{p}=.18$ ). For the former interaction, means for total number of perceptual pairs recalled grouped by grade 
TABLE 6

Mean Number of Perceptual Pairs Recalled

Grouped by Type and Stimulus

\begin{tabular}{c|c|c}
\hline Stimulus & Type 1 & Type 2 \\
\hline Conceptual & .21 & .14 \\
\hline Perceptual & 2.07 & .60 \\
\hline Unrelated & .28 & .03 \\
\hline
\end{tabular}


and type are presented in Table 7. Analysis of aimple main effects revealed that for Type 2, recall of perceptual pairs did not differ significantly between brades 1 and 6 . However, for Type 1, sixth-graders' recall was significantly guperior to that of first-graders. In addition, for firstgraders, recall between Type 1 and 2 conditions was not olgnificantly different. For oixth-graders, recall in Type 1 conditions was significantly superior to recall in Type 2 conditions. Thus the hypothesis regarding differential recall of sixth-graders under varying instructional conditions, and equivalent recall of flirgtmgraders under the vary same conditions, was supportah.,

Sex was not significant either as a main effect or in interaction with other variables. Number of Unrelated Pairs Recalled

The analysis of variance for this measure revealed significant main effects for grade ( $F=6.57$, df $=1 / 144, p=.01$ ), type $(\underline{F}=12.21, d f=1 / 144, \underline{p}=.001)$ and stimulus $(\underline{F}=22.35$. df $=2 / 144$. $\mathrm{e}(.001)$. Recall of unrelated pairs was olgnificantly superior for sixth-compared to first-graders, for subjects in Type 1 rather than Type 2 conditions, and for subjects in the unreinted stimulus colditions. For the latter Iinding, recall of unrelated patrs was significantly greater in the unrelated conditions compared to both the conceptual and perceptual conditions ( $p<.01$ for both comparisons) while the latter two did not diffor significantly from each other (as revealed by Tukey tests of paimwibe comparisons for marginal means). Thus, blocking of unrelated 
63

TABLE $?$

Mean Number of Perceptual Fairs Recalled

Grouped by Grade and Type

\begin{tabular}{c|c|c}
\hline Grade & Type 1 & Type 2 \\
\hline 1 & .50 & .26 \\
\hline 6 & 1.21 & .26 \\
\hline
\end{tabular}


pairs significantly influenced such recall.

Several significant interactions qualify the findings roported above. A significant Grade $X$ Type interaction $(\underline{F}=12.21, d f=1 / 144, p=.001)$, and a signficant Grade $X$ Type $X$ Stimulus interaction ( $\underline{p}=7.12, \underline{d}=2 / 144, \underline{p}=.002$ ) provided support for the hypothesis concerning the effects of type of task presentation. Analysis of simple main effects of the former interaction revealed that recall under Type 1 and 2 conditions did not differ significantly for firstgraders, For sixth-graders, however, Type 1 conditions produced superior recall realutive to Type 2. In addition, first- and sixth-graders' recall of unrelated pairs was not significantly different in Type 2 conditions, while for Type 2 conditions, sixth-graders' recall was significantly superior to that of first-graders. However, these findings are qualified further by the three-factor interaction, which revealed that the difference between first- and sixth-graders under Type 1 conditions existed only in the unrelated-pairs condition. Moreover, the significant difference botween Type 1 and 2 recall for 81 th-graders anso occurred only in the unrelated stimulus condition. In addition, for subjects in both grades, recall of unzelated pairs in the Type 1-unrelated condition was significantly superior to such recall in the conceptual or perceptual conditions ( $p<.01$ ) while the latter two conditions did not differ significantly from each other. Table 8 presents the means for total number of unrelated pairs grouped by grade, type and stimulus. A significant Type $X$ Stimulus interaction $(\underline{F}=16.16$, 
TABLE 8

Mean Number of Unrelated Pairs Recalled Grouped by Grade, Type and Stimulus

\begin{tabular}{l|c|c|c|c}
\hline \multirow{2}{*}{ Stimulus } & \multicolumn{2}{|c|}{ Type 1 } & \multicolumn{2}{c}{ Type 2 } \\
\cline { 2 - 5 } & Grade 1 & Grade 6 & Grade 1 & Grade 6 \\
\hline Conceptual & .00 & .21 & .21 & .07 \\
\hline Perceptual & .07 & .21 & .14 & .28 \\
\hline Unrelated & .71 & 2.21 & .42 & .14 \\
\hline
\end{tabular}


df $=2 / 144, p<.001$ ) indicated that there were no significant differences between stimulus conditions under Type 2 instructions. However, for Type 1 instructions recall of unrelated pairs was significanlty greater in the unrelated compared to both the conceptual and perceptual stimalus conditions ( $p<.01$ for both comparisons), while the latter two conditions did not differ significantly.

Sex was not significant. as a main effect or in Interaction with other variables. Number of Within Treatment Pairs Recalled

The analysis of variance of this measure revealed significant main effects for grade $(\underline{F}=11.31, \underline{d f}=1 / 144, p=.001)$ and for type ( $\underline{P}=60.88$, df $=1 / 144, \underline{p}<.001)$. Sixth-graders recalled significantly more pairs than first-graders, while subjects in Typo 1 recalled significantly more pairs than those in Type 2 conditions. These results are consistent with those reported above for the recall of conceptual. perceptual and unrelated pairs. Interestingly, the main effect for stimulus was not significant $(\underline{P}=2.45, \underline{d \rho}=2 / 144$, $\mathrm{p}=$.09) which indicated that there was no greater tendency for subjects in any of the stimulus conditions to recall relevant within condition pairs. Moreover, wh nonsignificant Grade $X$ Stimulus interaction $(\underline{F}=.08, d f=2 / 144, p>.50)$ indicated that the pattern of recall for differatt stimull was equivalent for both first- and sixth-graders. It appears that for the free recall of pairs, the physical pairing, rather thanthe type of relationshlp betweent the pairs, influenced performance. 
A significant Grade $X$ Type interaction $(\underline{F}=15.22, \underline{\text { df }}=1 / 144$, p <.001) revealed that while recall of within treatment pairs was signiflcantly greater in Type 1 compared to Type 2 conditions for both first- and sixth-graders, the difference between Type 1 and 2 conditions was significantly greager for sixth- compared to the difference for first-graders. In addition, as found for other measures, first- and sixthgraders' recall was equivalent under Type 2 conditions, while sixth-grade_ sobjeati recalled significantly more pairs than Pirst-graders only in Type 1 condifions. Table 9 presents the means for number of within treatment pairs recalled grouped by grade and type. The Grade X Type interaction is presented in Figure 5.

Sex was not significant as a main effect or in interaction with other variables.

Latency

The analysis of variance for this measure was conducted both with and without a $10 \mathrm{~g}$ transformation recommended by. Winer (1971, p. 400) for measures which are units of time. Results with and without the transformation were essentially equivalent. Therefore, results are presented for scores which were not transformed.

Significant main effects were obtained for grade ( $\underline{F}=5.07$. $d f=1 / 144, g=.02)$ and type $(\underline{p}=6.04, \underline{d f}=1 / 144, \underline{p}=.016)$. Firstgraders' latencies were signiflcantly longer than sixthgraders'. Latencies for subjects in Typ 1 vondisignificantly longer than for those in Type 2 conditions. There were no other significant wain effects or interactions. 
TABLE 9

Mean Number of Within Treatment Pairs

Grouped by Grade and Type

\begin{tabular}{c|c|c}
\hline Grade & Type 1 & Type 2 \\
\hline 1 & 1.19 & .50 \\
\hline 6 & 2.47 & .40 \\
\hline
\end{tabular}




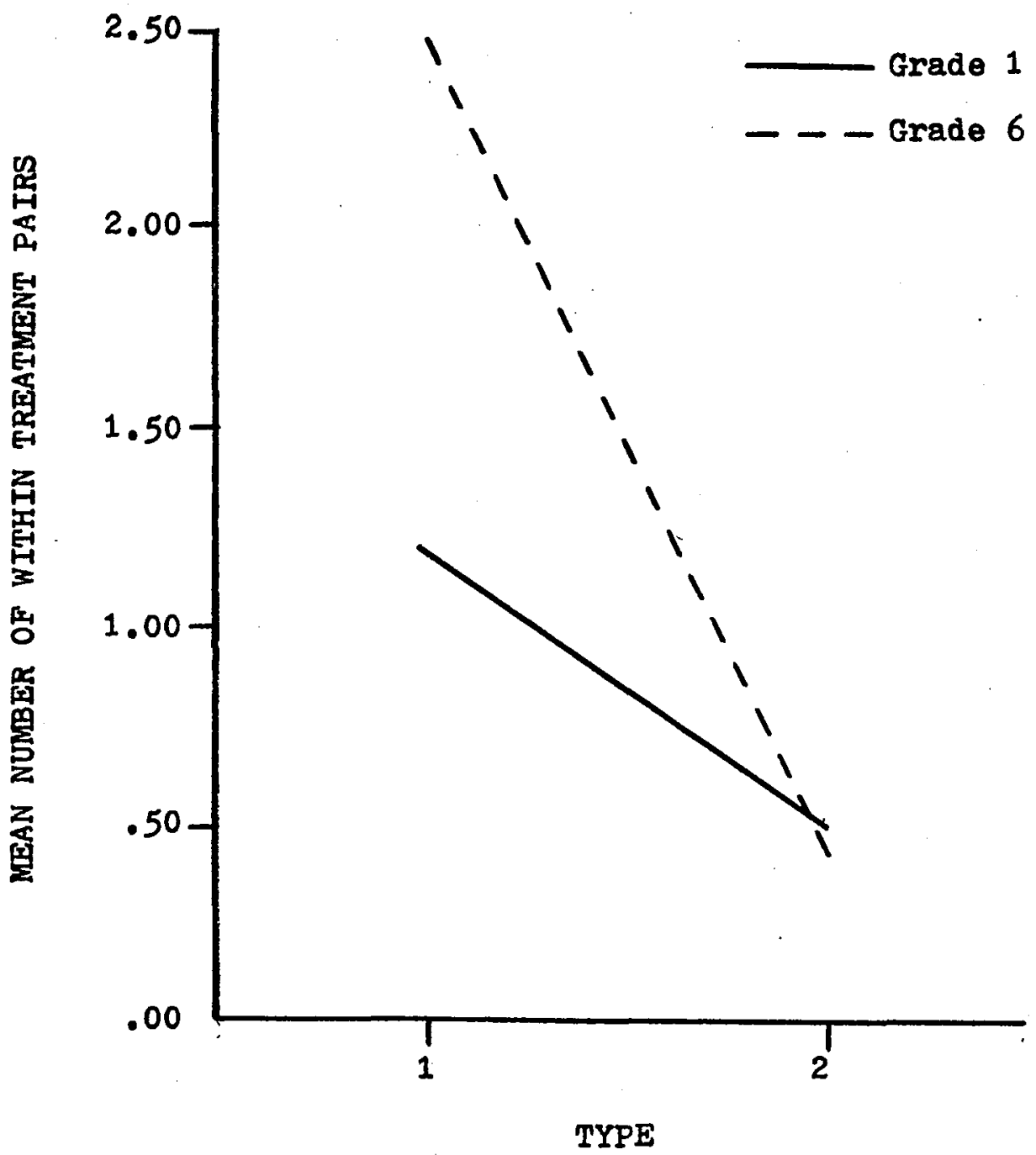

Figure 5. Grade $X$ Type interaction for the number of within treatment pairs. 
These findings for latency will be related to an explanation of the possible influence of response variables on the free recall of children of different ages, and will be discussed in the following chapter.

\section{Additional Data}

Incorrect matchings on the recognition of pairs task were scored as conceptual, perceptual, unrelated or other (neither conceptual, perceptual nor unrelated) across conditions. Table $I$ in the Appendix presents the mean number of matching errors grouped by grade, type and error type. Errors occurred predominantly in the other category. Additional trends mirror the results found for correct matching scores. More errors were made by first- compared to sixth-graders, and by subjects in Type 2 compared to those in Type 1 conditions. 
CHAPTER IV

\section{DISCUSSION}

According to the frexibility hypotheses advanced earlier, It was expected that the learning of older rather than younger children would be responsive to and differentiated by task demends and stimulus representation. These predictions recelved only limited support from the results of the present study. While the variables of type of task presentation and. to a lesser extent, stimulus representation did differentiate selectivity in children's learning, the results generally Indicated only a fow differences between the leaming patterms of younger and older children. A discussion of the evidence relevant to the two predictions will be presented first, followed by a separate section in which an analysis of the learnitg patterns which were obtained will be explicated.

\section{The Plexibility Hypothes:s}

\section{Type 1 VB. Type 2 Task Presentation}

The prediction for this factor was that older childran's Type 1 and 2 learning would be signiflcantly different, while that of younger children would be equivalent under both types of task presentation. The nost critical measures for this prediction were total number of correctly matched pairs, free recall of incidental stinuli, Intentional stimuli, pro- 
portion of intentional to total stimuli, and total number of stimuli recalled. The first measure of incidental learning is comparable to those of many previous Type 2 studies. The second incidental learning measure provides a direct assessment of incidental stimulus recall. Both the total intentional and proportion of intentional to total recall provide information as to whether subjects followed the task instruction differentially in experimental conditions. Total number of stimuli recalled indicates the influence of the experimental variables upon overall performance. While the matching of pairs measure of incidental learning did not support the flexibility hypothesis, analysis of the total number of incidental stimuli recalled provided partial confirmation. Both older and younger subjects demonstrated similar patterns of retention for the total number of correctly matched pairs measure. Retention of pairs was superior in Type 1 compared to Type 2 conditions, and the lack of interaction indicated that this trend did not differ by developmental level. The major difference between first-and sixth-graders was that the latter subjects' retention was superior in both Type 1 and 2 conditions. The increase with age of this type of incidental learning is particularly noteworthy since prior research found no evidence of an increase in incidental learning with age using unrelated pairs in Type 2 methodology (e.g. Hagen \& Hale, 1973). The use of meaningul stimuli in the present study may have been responsible for the difference between the current findings with those of previous investigators, and the trends found 
for Type 2 incidental learning measured by the matching of pairs in previous studies appear to be limited to the use of unrelated stimulus pairs. As Figure 4 reveals, in Type 2 conditions retention of unrelated pairs was quite poor and almost equivalent for both first- and sixth-graders, while retention of perceptual and conceptual pairs was superior to that of unrelated pairs, and conceptual pair retention increased with age. The presence of a meaningful or perceptual relationship may have increased the ease of remembering these latter pairs in subsequent retention tasks. Such pairs may have a higher probability of being remembered due to the possibility of being related to the subjects' already existing cognitive structures. For unrelated pairs, the absence of a meaningful relationship between pair members may have prevented subjects from relating pairs to cognitive structures since none may exist for these particular pairings. In the limited period of stimulus exposure, and with the presence of an intentional memory task, it may have been quite difficult for both younger and older subjects to create new cognitive structures, as through rote and associative learning processes. Therefore, younger and older subjects may have been at a relatively equivalent disadvantage for remembering unrelated stimulus pairs. This explanation may be applied to Type 2 developmental studies roviewed earlier. The combination of a concurrent intentional task, and the use of unrelated stimulus pairs may reduce the retention of intentional-incidental stimulus pair relationships due to the absence of cognitive structures with which the pairs may be readily related, and 
the limited opportunity for subjects to learn new associations. For these stimuli, since all subjects are at an equivalent disadvantage, incidental learning would not be expected to increase with age. On the other hand, for meaningful pairs incidental learning may be expected to increase with age since older subjects may have a greater number of meaningful cognitions with which to relate to the meaningful pairs.

For the free recall of incidental stimuli, both firstand sixth-graders' retention was significantly superior in Type 1 compared to Type 2 conditions. However, Type 1 conditions seemed to facilitate older children's incidental recall to a greater degree than that of younger children as evidenced by the significant Grade X Type interaction. Therefore, while incidental recall was differentiated according to Type 1 and 2 instructions for both younger and older subjects, the difference between recall under those conditions was larger for the latter subjects. These findings may provide limited support for the flexibility hypothesis since older subjects' performance seemed to be modified to a greater extent by Type 1 conditions than that of younger subjects. It is also noteworthy that Type 2 instructions decreased the incidental recall of all subjects to a similar level as evidenced by the lack of a significant difference between first- and sixth-graders' incidental recall in these conditions.

Though these two incidental learning measures appear to provide contradictory evidence regarding the flexibility hypothesis for type of task presentation, a comparison of the two measures reveals that the trends which were obtained 
complement each other. For both measures, first- and sixthgraders' incidental learning was superior in Type 1 rather than Type 2 conditions. Moreover, for both measures, the superiority of sixth- vs. first-graders' incidental retention seems to be smaller in Type 2 rather than Type 1 conditions. Though the interaction supporting this statement was obtained only for incidental stimulus recall, Figure 4 reveals that in Type 2 conditions first- and sixth-graders' matching of pairs is almost equivalent in the perceptual and unrelated stimulus conditions. Therefore, Type 1 and 2 conditions appear to exert similar influence on the incidental learning of younger and older subjects as measured in the present study.

The discrepancy of finding the significant hypothesissupporting Grade X Type interaction for incidental stimulus recall, but not for matching of pairs may be partially resolved by considering the difference between the nature of these retention measures. Matching of pairs relied on recognition which may have been an easier retention task than free recall of stimuli from which the incidental measure was derived. A retention cue is provided for the subject in the former but not the latter. Therefore, a discrepancy between younger and older children's incidental learning may be more evident when retention measures reflect processes associated with free recall (such as retrieval from memory without cues to help the learner identify stimuti; or storage of information in a form readily accessible for retrieval). The difference between patterns of incidental retention between older and younger subjects may be reduced when recognition measures are used. 
If this superiority in free recall situations is considered to be evidence for increased flexibility of older subjects, then an implication that can be derived is that flexibility is not an all-or-nothing phenomenon. Rather, certain learning processes may show a greater evidence of developmental differences in susceptibility to modification by instruction. The retention measure which taps the particular learning process may be an important determinant of whether or not differential flexibility between younger and older subjects is obtained, or interpreted as having been obtained.

Other measures, however, did not support the flexibility hypothesis regarding Type 1 and 2 instructions. Contrary to the prediction, younger subjects did not appear to be less capable of distinguishing between intentional and incidental stimuli in Type 2 conditions. Analysis of total number of intentional stimuli revealed that both first- and sixth-graders recalled signficantly more intentional stimuli under Type 2 compared to Type 1 conditions, though older children recalled more than younger ones. Moreover, if younger children had been unable to modify their performance in accordance with Type 1 and 2 instructions, then the proportion of intentional to total recall should have been similar across conditions. For older subjects who were hypothesized to be more flexible, the proportion of intentional to total recall should have been greater in Type 2 compared to Type 1 conditions. For the proportion of intentional to total stimuli, the relevant interaction which would have supported the flexibility hypothesis was not obtained. Both 
younger and older children showed a significantly higher proportion of intentional to total stimuli in Type 2 compared to Type 1 conditions (.75 and .51 respectively). Finding similar proportions for both younger and older subjects is particularly important since it indicates that despite older children's superiority in amount of learning, older and younger subjects' sebection of information components did not differ.

For total amount of free recall, sixth-graders' performance in Type 1 and 2 conditions did not differ significantly. However, younger children's total recall under Type 2 conditions was significantly superior to their recall under Type 1 instructions. Thus, according to the definition of flexibiIity used in the present study, younger children were more flexible than older ones for total free recall. This finding may indicate that older children are more likely than younger ones to spontaneously code stimuli even when not instructed to learn. This interpretation is further corroborated by the finding that sixth-graders' incidental recall was enhanced by Type 1 instructions to a greater degree than first-graders'.' These findings may be related to the issue of production deficiency in the development of memory skills. According to current theories of memory development (Flavell, 1970, Meacham, 1972) younger children evidence a production deficiency in memory tasks relative to older ones. Thus, the younger child may not be mediationally deficient, but does not spontaneously produce mnemonics or mediators for memory tasks. older children, on the other hand, do produce suitable mediators 
and/or mnemonic activities for recall. The notion that younger children were production rather than mediationally deficient is supported by the findings that an appropriate instruction (Type 2) improved their total recall level. The absence of a concurrent intentional task in the Type 1 condition may have allowed all children a greater opportunity to code incidental stimuli relative to those in Type..2 conditions. Older children may be more likely to engage in coding activities compared to younger children, not due to the inability of the latter, but to a greater number of years of practice in such activities of the former. For Type 2 tasks, both younger and older children may have used an appropriate learning strategy, such as repetition of intentional stimulus names and lack of incidental stimulus naming.

An additional or alternative interpretation of the facilitative effect of Type 1 conditions on older children's incidental learning and the facilitative effect of Type 2 conditions on younger children's total learning regards retrieval rather than encoding strategies. Older children may be more likely to organize, or use organizational properties of stimuli, to aid retrieval in free recall tasks. Older children may have responded to the relatively nonstructured Type 1 task by learning the organizational relationship between pair members. These organizational properties may then have served as retrieval cues for older subjects during free recall. Younger children may or may not have learned the relationships during stimulus exposure (due to posstible. 
production deficiency in the latter instance) but in either case may be less likely to use organizational properties of stimuli to cue recall in free recall tasks. The lesser degree of difference between younger and older children in Type 2 tasks can therefore be explained as due to the use of similar retrieval strategies by all subjects. Both younger and older children seemed to recall all intentional stimuli prior to incidental stimuli for Type 2 tasks. Type 2 instructions may therefore enhance younger children's learning relative to Type 1 instructions by affording these subjects an opportunity to provide themselves with retrieval cues.

Other findings of the present study support the interpretations. that younger children in Type 1 conditions seem to evidence production and/or retrieval inefficiencies. For the free recall of within treatment pairs, both first- and sixth-graders' performance was superior in Type 1 compared to Type 2 conditions. However, the Grade $X$ Type interaction indicated that Type 1 instructions facilitated the learning of older subjects to a significantly greater degree than that of younger subjects. Consistent with the findings for total incidental recall, there was no significant difference between first- and sixth-graders' level of recall in Type 2 conditions. The conclusion can thus be drawn that younger and older subjects' performance was differentiated between Type 1 and 2 instructional conditions. However, Type 1 instructions facilitated older subjects' total level of recall to a greater degree than that of younger subjects. Since within treatment pairs may be considered a measure of organi- 
zation, these findings suggest that in unstructured situations older subjects are more likely to produce mediators than younger ones and/or that older children are more likely to use the pair relationship to guide retrieval in the subsequent free recall task.

Results for free recall of perceptual and unrelated pairs further substantiate these trends. For these latter measures, sixth-graders' recall was significantly superior in Type 1 vs. Type 2 conditions, while first-graders' recall was equivalent under both instructional conditions. Further, firstand sixth-graders' performance did not significantly differ in Type 2 conditions. These findings could be interpreted as supporting the flexibility hypothesis. However, since other measures have established that both younger and older subjects showed differential performance in relation to Type 1 and 2 instructions, and when compared to the findings discussed above for recall of within treatment pairs, the findings for perceptual and unrelated pairs provide additional evidence that older children are superior at either encoding stimuli in unstructured tasks, or are better able to use organizational properties of stimuli for free recall retrieval compared to younger children.

In summary, results of analyses performed on the critical incidental and intentional learning measures provided little evidence to support the hypothesis that type of task presentation would differentiate the performance of older but not younger subjects. Both older and younger subjects were able to fdentify task-relevant from task-irrelevant stimuli in 
Type 2 conditions, and both age groups evidenced differential performance with Type 1 and 2 conditions. Retention of pairs (matching task) for first- and sixth-graders was superior in Type 1 compared to Type 2 conditions. However, it appears that there are developmental processes which affect the level of children's recall differentially by task condition. Type 1 conditions enhanced older children's incidental recall, and recall of within treatment, , perceptual and unrelated pairs to a greater extent than for younger children, while younger subjects' total recall was facilitated by a focusing instruction relative to older subjects'. These findings suggest that older subjects spontaneously code stimuli whether or not instructions for such activities are administered and/or that that they are more likely than younger children to use organizational properties of stimuli to aid retrieval in Type 1 free recall tasks.

Though the present author interprets the findings as not supporting the flexibility hypothesis, one could argue that the significant increase for sixth-grade subjects in Type 1 situations for the measures cited above relative to the recall of younger subjects is evidence for increased flexibility of the former. Since this increase produces a greater differential between the Type 1 and 2 performance of older subjects, one could reason that this is evidence for increased flexibility. The interpretation is equivocal, however, although the evidence is not. Since similar components of the tasks were learned by both older and younger subjects relative to the instructions, it is the view of the author that the superior recall of older subjects in Type 1 
situations indicates a tendency for these subjects to use organized memory strategles to a greater extent than younger childrenunder nonstructured conditions, rather than an increased ability to discriminate between task instructions than younger subjects. Therefore, the lssue of flexibility seems to be debatable, while the important issue involves delineation of the proeesses which influence the greater difference between older subjects' Type 1 and 2 performance relative to the difference for younger children.

Stimulus Representation

The prediction for this factor was that older children's learning would be differentiated according to the type of stimulus employed, while that of younger children would be equivalent across stimulus type. It was expected that learning of conceptual pairs would be significantly superior to learning of perceptual pairs which, in turn, would be significantly superior to the learning of unrelated pairs. for sixth-grade subjects.

Except for one interaction which lent, at best, weak. support to the general prediction, this aspect of the flexibility hypothesis was not confirmed by the data. This interaction indicated that for free recall of incidental stimuli, 8ixth-grade girls" recall was differentiated according to gtimulus type, while that of sixth-grade boys, and Iirgtgrade girls and boys was equivalent across stimulus typo. However, the direction of the obtained Interaction was at variance with the expectation that older children's recall for conceptual materials would be superior to that for 
other stimuli. Sixth-grade girlo' recall for incidental stimuli was equivalent in percoptual and unrelated conditions, which were both significantly superior to recall in the conceptual condition.

Variations in stimulus representation had very iftle effect on many of the measures analyzed. Thus, for free recall of intentional stimuli, proportion of intentional to total recall, and recail of within treatment pairs, stimulus type did not differentiate performance levels as a main effect, ir in interaction with grade. For total amount of stimuli recalled, stimulus represintection did not interact with grade. However, recall in the Type 2-conceptual condition was significaitly. superior to such recall in the Type 1conceptual condition.

One of the most interesting findings was obtained for the total number of pairs correctly matched. For this measure, stimulus differences had very strong effects. Watching of percoptual pairs was sienificantly superior to the matching of conceptual pairs, which, in turn, was significantly superior to the matching of unrelated pairs. In addition, the lack of interaction of the stimulus factor with any other Indicated that this trend was the same for Type 1 and 2 presentations (although Type 1 retention was significantly greater than Type 2 retention). For Type 2, Figure suggests that older subjects matched a greater number of conceptual pairs than younger subjecte relative to the difference of younger and older subjects' retention for perceptual and unrolated pairs. However, this trend was not statistically 
significant. Moreover, older subjects' retention of conceptual pairs was not different from their retention of perceptual pairs, which had been expected. Therefore, despite a very weak trend suggesting that younger and older subjectsmmay have differed in retention of pairs differing in stimulus relationship in Type 2 conditions, the results for Type 1 orerwhelmingly refute the prediction of differential flexibility for older subjects. For this measure, first- and sixthgraders' retention was significantly differentiated in similar manner by stimulus dimension.

In comparison with findings for other measures, it appears that stimulus type significantly affected incidental learning, but only for a measure which was sensitive to the cognitive process related to stimulus representation in the conditions of the present study. Moreover, the findings of similar trends for both age groups Indicates that younger and older children's selection of information in terms of perceptual, conceptual and unrelated categories is similar in incidental learning. These findings are contrary to those of 0lver and Hornsby (1966) using pictures as stimuli. The present study may indicate that perceptual information (color and shapsccues) is more salient to subjects of all developmental levels in incidental learning.

An important contrast to the findings for the matching of pairs task were those for recall of within treatment pairs. For the latter measure, retention levels were not differentiated by stimulus type for subjects of any age. Equivalent recall of pairs despite variation in stimulus relationship may indi- 
cate that the physical contighity in the blocked presentation of therpairs rather than the type of representation within pairs influenced free recall of pairs. It may be speculated that the matching of pairs measure is more reflective of attention factors, and perhaps of stimulus differences, than free recall measures.

In summary, since similar patterns were obtained for subjects of both age groups, it may be concluded that older subjects were not more flexible than younger silfects for the differantial learning of stimuli varying in type of representation within pairs. In addition, not all measures of incidantal learning were sensitive to differences in stimulus type. Rather than fault the meagures, it is important to consider the possibility that dfferent measures reflected the need for subjects to use different cognitive processes. Perhaps for the majority of measures employed in the present study, conceptual, perceptual and rote representation may not have played an important role in recell processes.

Results also indicated that sixth-grade girls" incidental recall was significantly differentiated by stimulus type. These findings may indicate a sensitivity of girls of this age to extemal stimuli. There have been no consistent trends for sex differences roported in the 11terature on childron's incidental learning. Approximately half of the studies surreyed did not report results for sex differences (Hagen, 1967, Hagen, Meachan, \& Mesibov, 1970, Hagen \& Sabo, 1967, Maccoby \& Hagen, 1965; Slegel \& Stevenson, 1966, Vaughan, 
1968). Of those that did report such results, three studies found no sex differences (Hale \& Piper, 1973, 1974, In press: Stegel \& Corsini, 1969). Results of other studies were inconsibtant. For instance, boys recalled more intentional stimuli than girls (Druker \& Hagen, 1969) while Schucker (1972) reported that Iffth-grade girls' intentional recall was superior to fifth-grade boys', while boys recalled more incidental stimuli than girls. Noreover, the support found for the hypothesis (of the present study) by the instance reported above (Bixth-grade girls' incidental recall) is not broad onough to support the prediction of flexibility for older subjects.

\section{Selective Leaming Trends}

\section{Type 1 vg. Trpe 2 Tagk Presentation}

As noted in the introduction, trends emerging from provious studies suggested that in Type 1 designs, older subjects learned more than younger ones, and thus were 1088 selective. On the other hand, In Type 2 designs older children appeared to be more selective in that incidental learning renained stable across age, while intentional learning increased. It was also noted that trends for Type 1 and 2 designs had boen found in studies using varying stimuli and methodologies. Thus, the comparison of both methods using the same stimuli and procedures, except for the initial instructions, allowed for the determination of whether the developmentel trends in selectivity are divergent. The present discussion will focus specifically on developmental 
similarities and differences in the two designs and will also attempt to show that a definition of selectivity based sololy on total amount of learning is inadequate for studying selective leaming.

Results for the total amount of stimuli recalled indicated that for both Type 1 and 2 learning older subjects recalled more stimull than younger ones. Therefore, if total amount of lemrning were to be used as a criterion of selectivity, then it could be concluded that older childzen are less selective than younger ones for both Types 1 and 2 designs. However, analysis of the components of total amount of learning and their patterns relative to Type 1 and 2 instructions revealed that seirective-learning differed sharply between the two instructional conditions, and that the trends were similar for subjects of both age levels.

Although the definition for both Type 1 and 2 incidental leaming is that which occurs in the absence of an instuction which signifies later retention tests (Postman, 1964!, results of the present study indicate that learning under both types of instructions is quite different despite the similarity of stimuli and presentation conditions. The major offect. of the Type 2 instruction was to bahance recall of the intentional stimulus relative to the Type 1 instruction. A second effect of the Type 2 instruction was to restrict leaming of the incidental stimulus, and relations between intentional and incidental stimuli, relative to Type 1 instructions. For Type 1, approximately $50 \%$ of recall was intentional, and $50 \%$ was incidental. On the other hand, 
for Type 2 conditions, approxinately 75\% if recall was intentional, and $25 \%$ was incidental. Moreover, the relationship between type and proportion of intentional to total recall was the same for subjects at both grade levels. These results suggest that subjects responded to the "I00k at" instruction by observing the top and bottom stimuli to an equivalent degree (perhaps due to the paired presentation), while instructions to "remember the top stimulus served to focus learning of one set of stimuli at the expense of the other (despite the presentation of paired stimuli). Moreover, the type of relationship between intentional and incidental stimuli did not interfere with intentional learning in Type 2 designs, although it did influence incidental learning. Thus, Type 1 and 2 instructions produced different selective learning strategies despite the presentation of identical stimuli in both conditions. Younger subjects showed neither an inability to discriminate task-relevant from irrelevant stimuli in Type 2 conditions, nor an inability to distinguish between "remember" vB. Ylook at" instructions. This latter point is similar to a recent finding by Yussen, Gagne, Gargiuli and Kunen (1974). These investigators found that children as young as seven learned moze when instructed to remember rather than look at stimuli in a free recall task. In the present study, the major difference between younger and older subjeots' intentional and incidental recall seemed to be in the total amount of such learning, rather than in the type of information discriminated. The conciusion I0x Typo 2. designs alffers somewhat from 
that of Hagen and Hale (1973). These authors proposed that younger children are nonselective in attention deployment relative to older ones since intentional learning increased while incidental learning remained constant across age. (Ogpelastothodology described in Chapter 1 of this paper was employed by these investigators.) Interpreting these trends by referring to Neisser's (1967) two-stage theory of attention, they concluded that the difference between younger and older children seemed not to be in the first stage of attention deployment in which discrimination of task-relevant and irrelevant stimuli occurs (though they reason that older children may impoove at this level as well), but in the second stage in which maintaining attention to task-relevant stimuli while ignoring irrelovant aspects occurs (focal attention). While the present author would agree that both younger and older children are able to initially discriminate relevant and irrelevant information, the conelusions advanced above for the results of the present study disagree with those of Hagen and Hale concerning the maintenance of attention to relevant v8. irrelevant stimuli. In particular, the data on proportions of intentional and incidental stimuli in total recall indicate no difference in the ability of older and younger subjects to maintain attention to components of the leaming tasks. Other data which also seom to disagreo with the viewpoint of Hagen and Hale were those obtained for the matching ofppairs. Older and zounger children demonstrated equivalent patterns of discriminating stinulus differences In both Type 1 and 2 conditions. Had younger children been 
unable to maintain attention to such relationships, then a lack of difference between recall of pairs in different conditions should have been obtained for these subjects. This was clearly not the case. Rather than a difference in attention deployment or maintenance, the data of the present study suggest that both older and younger children discriminate and maintain attention to relevant and irrelevant stimuli, though older children recall nore information than younger ones. iTotal amount of learning does not appear to be a suitable criterion for assessing selectivity in attention and learning. A more reasonable criterion seems to be patterns of learning within and between grades, regardless of absolute recall levels.

In light of the present findings, results of previous studies using Type 2 designs may be reinterpreted to support the explanation of similar selectivity patterns of older and younger children. For example, though prior studies using the Type 2 design did not use directly comparable measures of intentional and incidental learning, and, therefore, comparable proportions of such learning could not be examined as in the present study, patterns of intentional and incidental retention reveal similarities for older and younger subjects. Intentional learning was superior to incidental learning for all subjects (Hale \& Plper, 1973, 1974, Hagen, 1967, Hagen, Meacham, \& Mesibov, 1970, Maccoby \& Hagen, 1965, Wheeler \& Dusek, 1973). The general finding in these studies that incidental learning did not increase with age (Hagen \& Hale, 1973) may be indicative of the equivaient difficulty:- 
for younger and older subjects of learning unrelated intentional-incidental stimulus pairs concurrently with an intentional task. In addition, experimental variables such as spacing (Druker \& Hagen, 1969, Wheeler \& Dusek, 1973), verbal labeling (Wheeler \& Dusek, 1973), and physical integration vs. nonintegration of stimuli (Hale \& Piper, 1974) affected incidental and intentional learning significantly and similarly in younger and older children. Therefore, with regard to Type 2 designs, the findings of the present study do not appear to contradict those of previous investigations. Rather, earlier findings may be reinterpreted to be consistent with those of the present study.

Type 1 and Type 2 learning differed in other respects as well. Stimulus pair relationships were recalled to a significantly greater degree for every measure in the former. Type 2 instructions appeared to restrict free recall of pairs, and to a similar degree for subjects of both grade levels. It is important to note, however, that the relationship between pairs was discriminated in Type 2 as demonstrated by stimulus differences in subjects' performance on the matching of pairs measure. Thus, the activities involved in Type 2 learning presented in this study may have interfered with the free recall of pairs as children may have been inclined to report the intentional stimuli contiguously in response to the initial instruction. Free recall of pairs may have been more difficult than recognition of pairs, and perhaps involve different retrieval processes. Even for Type 1 
conditions free recall of pairs was infertor to recognition. Therefore, the combination of intentional task instructions, and the difficulty of free recall of pairs, may have been responsible for absence of stimulus differences in free recall of pairs measures for Type 2 conditions.

The comparison of younger and older children's learning of components of Type 1 and 2 tasks revealed that selective patterns do not appear to differ markedly. It appears that selective learning trends of younger and older children are not divergent. Rather, selectivity of all subjects was influenced by Type 1 and 2 differentially, apparentiy due to the presence of a concurrent intentional task in the latter. To the extent that this task interferes with, or restricts Iearning of the incidental stimulus and relationships between intentional and incidental stimuli, the incidental components are less likely to be coded and/or retrieved during recall tasks. This apparently affects subjects ranging in age from early to later childhood. Thus, incidental learning of this type would be unlikely to increase with age since the opportunity for subjects of ang age to code stimuli is unavailable. However, if the incidental stimulus is related in some manner to the intintional stimulus ( as in intrinsic incidentil stimuli, or by relating pairs on a meaningful dimension) then such incidental materials may have a higher probability of being coded or rehoarsed, and may be more readily retrieved from memory (though retrieval may be more likely in recognition rather than recall tasks). Therefore, Type 2 incidental learning may then be more likely to 
increase with age, as found by Hale and Piper (1973) for intrinsic incidental stimuli (Type 2) and in the present study for meaningfully related incidental stimuli (Type 2, measured in the matching of pairs) due to the hypothesized superior memory abilities of older subjects. In Type 1 designs, since there is no intentional task to interfere with incidental learning, the incidental stimulus is not excluded from learning activities. Therefore, due to the relative encoding and/or retrieval efficiencies of older subjects, incidental learning increases with age.

Relative to Postman's (1964) analysis of incidental learning, the present results for Type 2 learning indicated that the intentional instructions did not generalize to the incidental stimuli. This finding is consistent with that of Rosenberg (1962) in a comparative study of Type 1 and 2 designs with adults as subjects. Rather, intentional instructions inhibited learning of the incidental stimuli, a finding similar to that of Figcher and Cook (1962) for adults. While Postman's view is that the occurrence of such restriction is due to the competition between responses made by the subject to both intentional and incidental stimuli, an alternative explanation may be that for children, responses are not made to the incidental stimuli. The subject may briefly examine and then ignore the incidental stimuli in his or her attempt to learn the intentional stimuli. Limited incidental learning could then be explained by subjects' initial or random eye movements to the incidental stimulus. In comparison, for Type 1 designs, children's eye movements to intentional 
and incidental stimuli should be equivalent. Fischer and Cook (1962) suggested another interpretation. They proposed that the motivation aroused by intentional learning restricted subjects' perception of incidental stimuli.

For Type 1 designs, the results of the present study confirm trends reported earlier. With or without the presence of orienting tasks, there is an increase in incidental learning with age. Postman (1964) hypothesized that the orienting tasks increase incidental recall due to the opportunity they afford subjects to engage in cue-producing (representational) responses to the materials. The results of the present study suggest that even an instruction with minimal task structure, such as "look at" is sufficient to activate mediation in older subjects, and to a vastly greater degree than for younger subjects. Older subjects, then, seem to produce their own orienting tasks relative to younger ones. An important issue concerns this phenomenon. Why do older children spontaneously engage in mediatory activities despite the lack of an apparent goal? It may be speculated that older children spontaneously produce such activities (such as labeling or categorization of stimuli) for symbolic mastery of the environment (competence motivation as suggested by White [1959]), or for the intrinsic satisfaction of performing the activity (intrinsic motivation as suggested by Ausubel [1968]). Another possible explanation is that: older children expect to use the information which is currently presented for a subsequent task, and thus attempt to learn it. Younger children, on the other hand, may not yet have adopted this orientation. 
If older children do produce self-orienting activities spontaneously, then overt orienting tasks imposed by the experimenter should benefit younger children to a greater degree. Such tasks would allow younger subjects the opportunity to produce relevant mediators for materials, and thereby alleviate the hypothesized production and/or retrieval inefficiencies of younger children in Type 1 incidental learning. Since Type 2 instructions in the present study enhanced younger subjects' total recall to a significantly greater degree than that of older subjects, the suggestion that orienting tasks would facilitate younger children's incidental learning to a greater degree than older children's seems even more likely. These speculations may be easily tested.

A developmental analysis of Postman's (1964) views on incidental learning, therefore, requires further study of the nole of orienting tasks in Type 1 and 2 designs. Further, it is important to determine whether older subjects' improved Type 1 learning, and Type 2 intentional learning, is due to initial coding of stimuli, or the ease with which children of different ages are able to retrieve information. Manipulating such variables as the presence or types of orienting tasks, and cued vs. noncued recall, may help to elucidate these processes. In addition, since postman states that incidental and intentional learning are similar due to comparable functional relationships between stimuli found in studies with adults, it is important to determine if this similarity is characteristic of children's incidental and intentional learning as well. Another point suggested by the results of the present study is that production deficiency and efficiency may not 
be related to "planfulness" (Flavell, 1970, p. 205). In Plavell's view, general planfulness oriented towards an intentional goal may be a prerequisite for the use of specific memonic activities appropriate to a given task. Thus, an increase in planfulness would be one of the factors associated with a decrease in production deficiency. However, according to Postmen (1964) it is the activity of the learner, rather than the intention, which influences learning. For example, incidental and intentional learning can be equivalent despite the lack of an intentional goal of the former if subjects produce representational responses, as when orienting tasks are provided. The results of the present study appear to support this latter view. Since production efficiency of older subjects relative to younger ones was observed in a task with no apparent intentional goal, then planfulness may not play an important part in production efficiencies of older children.

\section{Stinulus Representation}

The findings regarding the retention of stimuli varying in type of representation as measured by the matching of pairs do not appear to be supportive of Bruner's (1966) theory of the development of representation. For all children, porceptuai pairs wore matched to a significantly greater degree than conceptual pairs, while unrelated pairs were most difficult. According to Bruner's theory and data reported by 0Iver and Hornoby (1966) it would have been expected that older children's conceptual pairings exceeded their retention 
of perceptual pairs, al though younger children's performance may have been expected to be consistent wits: the trends which were obtained.

These findings raise the question of whether there is a difference between the type of representation employed by younger and older children of elementary school age. If these results were not supported by other findinge in the literature, then they could be attributed to the fact that incidental learning methodology was employed. It may have been argued that older subjects adopted a more primary learning strategy due to the lack of intentional instructions for the learning of pairs. Thus, it could have been concluded that older subjects may use conceptual representation to a greater extent than perceptual in intentional rather than incidental learning, while younger subjects use ikonic representation in both.

However, other investigators have found that older and younger children, and adults, use similar forms of representation. Miller (1973) conducted a study to test Bruner's hypothesis that younger and older subjects differ in their use of concrete and abstract representation. Using definitions of concrete and abstract which were analogous to the perceptual and conceptual conditions of the present study, eight groups of four objects oach were created such that they could be grouped either perceptually or conceptually by removing an object. Children with a mean age of $6 \frac{1}{2}$ years, and college students with a mean age of 19 years, were asked to group each set of objects twice by removing a different 
object to form a different subset of three from the original four. It was found that there were very few differences between the types of categorles grouped by younger and older shbjects. Moreover, for both children and adults, the majority of goupings were abstract rather than concrete. The correspondence between the present findings and those of Milier is the similarity of younger and older children's use of representation. The two studies differ in that abstract exceeded concrete groupings in Miller's study, while retention for perceptual pairs was superior to conceptual retention in the present study. This discrepaney may be due to the possibility that perceptual characteristics are more salient than conceptual cues in incidental as opposed to intentional learning. If this is 80 , then the equivalence of learning processes in incidental and intentional learning espoused by Postman (1964) may be questioned. Subjects may be differentially sensitive to qualitative aspects of stimuli in incidental and intentional situations. The comparison of conceptual and perceptual categorization in incidental v8. Intentional learning should be investigated. Bousfield, Esterson and Whitmarsh (1958) found that in an intentional free recall task in which conceptual and perceptual (color) groups of atimuli were presented. there was no difference in perceptual clustering between third-graders and college.students. Moreover, for thirdand fourth-graders, and college students, there was a greater degree of conceptual v8. perceptual clustering. However, a significant increase in conceptual clustering with age 
was observed, which may have been attributable to the superlority of older subjects production of information organized by category. Bousfield et al., however, used conceptual categories which were not controlled for percoptual similarity. For example, three of the items in the fruit category were melon, lime and apple. All of these items have similar shapes. Therefore, clustering for these itams may have been based on a combination of conceptual and perceptual characteristics. Integrating the results of the present study with those of Miller (1973) and Bousfield et al. (1958), there is a lack of evidence to support the hypothesis that younger children use perceptual categories to a greater degree than older ones. Further, there is no evidence that young children are unable to group itams in an inferential, nonperceptual muner. However, incidental and intentional instructions may enhance different forms of representation, producing better retention of perceptual rather than conceptual in the former, and superior conceptual relative to perceptual performance in the latter.

It is possible that differential use of perceptual and abstract representation may be observed at an earlier age. One may speculate that differences in the use of ikonic and symbolic representation diminish when the child begins to use language symbolically. Since language (labels) may be nonperceptual equivalents to referents, their use by young children may evidence a general capacity for symbolic representation in linguistic and nonlinguistic spheres. In later years there may be an increase in the scope of concepts 
employed, the comprehension of concepts, the number of items which are subsumed in a category, or the syntax of categories, but these processes may represent elaborations of a general ability to use inferential concepts which emerges early in life. Another possible explanation of the discrepancy between the present data and the findings of olver and Hornsby (1966). whose findings supported Bruner's theory, concerns methodology. There may be differences between younger and older children's tendency to use perceptual and symbolic representation in free vs. constrained grouping tasks. A major difference between the methodology of Olver and Hornsby (1966) and that of the present study, Miller's (1973) study and that of Bousfield et al. (1958) concerned the dimension of freedom vo. constraint in categorization. In the former study, subjects were asked to group together any of 42 pictures on any basis. In all of the latter three studies, subjects were presented with groups which had been selected by the investigators. Rather than create his or her own groups, subjects were forced to determine equivalence of preformed categories. Free cholces may reflect subjects' preferences rather than their capacities for certain groupings. This hypothesis may easily be tested, and is important due to discrepancies between findings and theory.

The superiority of perceptual-stimulus retention was limited to subjects in the perceptual-stimulus condition. Subjects in other stimulus conditions made relatively few perceptual-matching errors. The overwhelming majority of errors were not ruleguided.: Subjects apparently did not use perceptual similarities between stimuli as a minimal cue to facilitate retention unless 
such cues were overt, as in the appropriately paired condition. Relatively brief exposure intervals and/or the activities associated with leaming the pairs which were exposed may have deterred, subjects from noticing implicit relationships between stimuli.

As a conclusion to this section, implications of the present study are that the type of representation between stimuli is important in incidental learning, with perceptually- and conceptually-related stimuli producing superior recognition compared to unrelated stimuli. However, physical characteristics of stimulus presentation may be relatively more important than stimulus representation for free recall as opposed to recognition measures, as evidenced by the lack of significant stimulus differences obtained for the free recall measures discussed earlier. The degree of influence of perceptual and physical characteristics of stimuli in incidental tasks should be compared with the influence of such factors in intentional tasks. Perhaps for the latter, instructions may affect recall over and above the influence of perceptual features.

Other Implications of the Data

\section{Iatency}

Younger children's latencies for free recall were significantly longer than those of older subjects. This finding may be related to the conclusions by Wickens (in press) that children's reaction times decrease as a function of age from three years to adolescence despite controls for attentiveness, motivation (incentive) and practice. Neimark, Slotnick and Ulrich (1971) also found that college students recalled more information in significantly less time than third-and fourth-graders. The impli- 
cation is that longer response latencies do not indicate that subjects are spending a greater amount of time studying relative to those spending a shorter time. Response variables may be associated with the differences between younger and older children's absolute levels of recall. Perhaps retrieval speed is a significant factor, since increased speed may reduce the possibility of forgetting. It is also conceivable that older children use more organized retrieval mechanisms than younger ones which may result in shorter latencies. The present study cannot determine whether either of these possibilities is valid. However, the need to consider encoding and response variables as distinct sources of memory differences in children's recall is suggested by the data. The production deficiency hypothesis should perhaps be examined in terms of encoding, retrieval and response production deficiencies.

Shorter latencies for subjects in Type 2 compared to those in Type 1 conditions may indicate that the former subjects had been prepared for the recall task by the intentional instruction. Incidental and Intentional Free Recall

Several results from the present study may be compared with those of intentional free recall studies. In a review of literature on children's free recall, Jablonski (1974) reported that total recall increased with age in both single- and mulititrial tasks and for a variety of materials. The results of the present study for total free recall of Type 1 and 2 designs are consistent with this trend. Furthermore, Jablonski reported that clustering seems to increase with age, although the evidence is somewhat contradictory. In the present study, older children in Type 1 conditions recalled significantly more pairs than 
younger subjects. Thus, older children seem capable of producing a significantly greater amount of organized recall than younger subjects in incidental and intentional leaming. Jablonski also reported that the bloding of category instances facilitated clustering to a significantly greater degree than random presentation of the instances within the list. Similar results were found in the Type 1 conditions of the present study. However, amount of recall between stimulus condition did not differ. This finding is of importance to theories of organization in recall. The implication is that the physical presentation (blocked pairs) rather than the type of relationship between stimuli affects organization in free recall. This finding may be limited to incidental learning since the absence of an intentional instruction may reduce subjects' apprehension and/or rehearsal of stimulus relationships. However, if intentional free recall studies were to obtain similar findings (that the type of category was not as important as the physical blocking of categories for free recall clustering) then a contiguity interpretation of clustering would be supported. According to this interpretation, free recall of blocked categories may be due to the contiguous occurrence of category instances which increases the likelihood that they will be rehearsed together (interpretation suggested by a theoretical proposal of Wallace [1971]). Blocking of meaningful and nonmeaningful items should be conducted in intentional learning to determine whether the phenomenon observed in the present study is limited to incidental learning. The use of pairs in the present study may have also influenced the lack of stimulus differences. When a larger number of 
category items are used, stimulus differences may be more apparent due to the possible difficulty of subsuming a large number of items within a category. In this instance, conceptual groups may facilitate recall to a greater extent than blocking of items.

Conclusion

The hypothesis of increased flexibility in the selective learning of older subjects received only minor and limited support. In general, younger and older subjects learned similar components of the tasks. The results did not appear to support the view that young children are deficient in the ability to differentiate task-relevant from irrelevant information, Type 1 vs. Type 2 instructions, or stimulus relationships. However, developmental differences were obtained. Older children were superior to younger ones in their total level of recall. This was especially marked in unstructured (Type 1) conditions. Explanations regarding possible production and/or retrieval inefficiencies of younger relative to older subjects were advanced to account for these differences. Whether recall efficiency of older subjects is evidence for increased flexibility is a matter of interpretation and/or semantics. Rather than use the label, it is more important to elucidate processes accountable for memory differences. Suggestions for investigating these processes were proposed earlier. The confusions and contradictions evidenced in reviews of children's incidental learning, as noted in the introduction, 
appear to be the result of the failure of these authors to distinguish between Type 1 and 2 designs. It is evident from the results of this study that these two methods result in different patterns of selective learning. Moreover, when Type 1 and 2 designs are viewed concurrently, the developmental trends are not paradoxical or contradictory, but are related to specific learning processes entailed by task requirements.

Multiple measures appear to be essential in studying incidental learning. For the present study, the measures apparently tapped different processes since results for each measure were not redundant with those for other measures. The measures were complementary, and provided an overall view of the processes involved in incidental learning. Moreover, omitting a measure may produce a significant loss of information. For instance, if the matching of pairs measure had not been included, it would have appeared as if neither older nor younger subjects discriminated stimulus relationships.

The distinction between attention and memory factors needs further clarification. Methods to distinguish between these factors need to be devised. One possibility way be the measurement of subjects' physical orientation through eye-tracking devices. Correlations between patterns and amount of scanning with retention measures may halp to distinguish between attention and memory. Since most studies of children's inoidental learning have been conducted with visual materials, the generality 
of the trends needs to be extended to other sensory modalities. Doyle (1973) provides evidence that Type 2 incidental leaming trends in the aural modality are similar to those for visual stimuli. Hore evidence of this type is needed to determine whether the trends found appear to be general information processing characteristics regardless of modality. or whether sensory modality provides different patterns of relationships between instructions and stimulus type. Where may also be developmental differences in this type of learning between sensory modes.

\section{Educational Implications}

With the advocacy of more fluid instructional procedures in recent years, such as open classrooms and discovery learning, the role of incidental learning may be of great potential to instructional techniques. Autoinstructional methods and an increase in freedom of choice of subject matter by students may onhance the status of incidental leaming in classrooms. Extrapolating from: the results of the present study, older students may profit from a lack of intentional instruction (Type 1) to a greater degree than younger (primary grade) ; stiudents. Unstructured situations may be more ouitable for older, students since they may be able to apply organizational strategies more efficiently than younger students in these instances. Thus, there may be an optimal developmental level at which to begin unstructured classroom practices.

Implications of Type 2 designs are that instructions to memorize may be effective in improving intentional recall 
for both older and younger students. However, such instructions may serve to deter the formation of meaningful relationships between intentional and incidental learning materials. For example, it is often desirable for children to integrate information from one subject area with that of another. If children memorize facts from each of the two areas (intentional learning) they may fail to see the relationship between these two areas (incidental learning). Memorization may interfere with comprehension of meaningful relationships between or within subject areas, or may restrict children's attention to that which he or she is to remember. A deemphasis on memorization in schools would thus be advisable. At present, many classrooms are Type 2 learning situations. The eff1clency of such arrangements is questionable if learning of meaningful irelationships is to be emphasized.

The paraliels between educational practice and Type 1 and 2 incidental learning are significant, and research as to the relationships between incidental learning, developmental processes and instructional techniques should be conducted. 
APPENDIX

\section{Criteria for Construction of Stimulus Pairs}

Word association norms for children developed by Entwisle (1966) and Palermo and Jenkins (1964) were used as sources for stimulus items which had little or no associative relationship. These norms were developed on samples of elementary school children who were similar in age and social class background to the present sample. Sixteen nouns which could be portrayed pictorially were chosen such that eight stimulus terms which had appeared in either the Entwisle or Palermo and Jenkins norms (or both) were paired with eight response terms which were not among the five most common associates to the stimulus terms. If a word was not among the first five most common response associates to the stimulus words, its frequency of occurrence as a response was very low. These eight pairs formed the group which were related on a conceptual basis. In all cases, the pairs had very infrequent occurrences on the association norms. Interitem, between pair associativity was also quite low. Perceptual and unrelated pairs were constructed by rearranging these 16 stimuli with the additional restriction that a pair could not be repeated within another stimulus condition. Thus, a single pair could be either conceptual, perceptual or unrelated, but could not overlap with any other condition. The word association norm lists were referred to in each 
instance. to control for intra- and interpair associativity. Due to the necessity of repairing two sets of eight stimuli with various experimental constraints, 3 of the 24 pairs created did not have stimulus members appearing as stimulus terms on the association norms. Thus associations for these words were not established. In order to create pairs which were Ifkely to be low in associative relatedness, criteria which had been found to be typical of children's word associations (Cramer, 1974; Moran \& Swartz, 1970; Penk, 1971) were considered. Thus, these words were not paired if they were contrasts, synonyms, superordinates, logical coordinates, or syntactically related. The three pairs which were developed according to these criteria were face-egg (perceptual condition), tent-sun and face-kite (both in the unrelated condition). Pretesting indicated that the intended relationahip had been established, and that the members of these pairs were not likely to be related by association.

The frequencies of occurrence of the eight intentional and eight incidental stimuli were of similar magnitudes according to the Thorndike and Lorge (1944) G count. of the intentional stimuli, five occurred in the most frequent category per million words, and three occurred in the second most frequent category. For incidental stimuli, six were rated as occurring in the most frequently occurring category per million words, while one occurred 47 times per million, and another occurred 10 times per million. Since these Irequencies are not current, they should be considered secondary to the pretesting data. 
TABLE A

Means and Standard Deviations for Total Amount of Stimuli Recalled Grouped by Grade. Type and Stimulus

\begin{tabular}{|c|c|c|c|c|c|c|c|c|}
\hline \multirow{3}{*}{ stimulus } & \multicolumn{4}{|c|}{ Type 1} & \multicolumn{4}{|c|}{ Type 2} \\
\hline & \multicolumn{2}{|c|}{ Grade 1} & \multicolumn{2}{|c|}{ Grade 6} & \multicolumn{2}{|c|}{ Grade 1} & \multicolumn{2}{|c|}{ Grade 6} \\
\hline & $M$ & SD & $M$ & $S D$ & $M$ & SD & $M$ & SD' \\
\hline Conceptual & 5.21 & 2.11 & 8.78 & 1.92 & 6.92 & 1.90 & 8.85 & 1.23 \\
\hline Perceptual & 4.85 & 1.79 & 8.64 & 2.62 & 6.35 & 1.39 & 8.85 & 1.56 \\
\hline Unrelated & 4.71 & 1.59 & 10.07 & 1.77 & 5.57 & 1.08 & 8.07 & 1.77 \\
\hline
\end{tabular}


TABLE B

Means and Standard Deviations for Number of Intentional Stimuli Grouped by Grade, Type and Stimulus

\begin{tabular}{|c|c|c|c|c|c|c|c|c|}
\hline \multirow{3}{*}{ stimulus } & \multicolumn{4}{|c|}{ Type 1} & \multicolumn{4}{|c|}{ Type 2} \\
\hline & \multicolumn{2}{|c|}{ Grade 1} & \multicolumn{2}{|c|}{ Grade 6} & \multicolumn{2}{|c|}{ Grade 1} & \multicolumn{2}{|c|}{ Grade 6} \\
\hline & M & SD & M & $S D$ & $M$ & SD & $M$ & SD' : \\
\hline Conceptual & 3.07 & 1.07 & 4.50 & 1.09 & 5.21 & 1.18 & 6.64 & 1.00 \\
\hline Perceptual & 2.50 & 1.16 & 4.14 & 1.65 & 4.51 & 1.34 & 6.64 & 1.08 \\
\hline Unrelated & 2.42 & 1.22 & 4.76 & 1.47 & 4.07 & 1.54 & 6.21 & .89 \\
\hline
\end{tabular}


TABLE C

Means and Standard Deviations for Number of Incidental

Stimuli Grouped by Grade, Type and Stimulus

\begin{tabular}{|c|c|c|c|c|c|c|c|c|}
\hline \multirow{3}{*}{ Stimulus } & \multicolumn{4}{|c|}{ Type 1} & \multicolumn{4}{|c|}{ Type 2} \\
\hline & \multicolumn{2}{|c|}{ Grade 1} & \multicolumn{2}{|c|}{ Grade 6} & \multicolumn{2}{|c|}{ Grade 1} & \multicolumn{2}{|c|}{ Grade 6} \\
\hline & $M$ & SD & $M$ & SD & M & SD & $M$ & SD? \\
\hline Conceptual & 2.14 & 1.29 & 4.28 & 1.32 & 1.71 & 1.32 & 2.21 & .69 \\
\hline Perceptual & 2.35 & 1.15 & 4.50 & 1.34 & 1.78 & 1.05 & 2.21 & 1.62 \\
\hline Unrelated & 2.28 & .82 & 5.28 & 1.06 & 1.50 & 1.16 & 1.85 & 1.51 \\
\hline
\end{tabular}


TABLE D

Means and Standard Deviations for the Proportion of Intentional to Total Stimuli Grouped by Grade, Type and Stimulus

\begin{tabular}{|c|c|c|c|c|c|c|c|c|}
\hline \multirow{3}{*}{ Stimulus } & \multicolumn{4}{|c|}{ Type 1} & \multicolumn{4}{|c|}{ Type 2} \\
\hline & \multicolumn{2}{|c|}{ Grade 1} & \multicolumn{2}{|c|}{ Grade 6} & \multicolumn{2}{|c|}{ Grade 1} & \multicolumn{2}{|c|}{ Grade 6} \\
\hline & $M$ & SD & M & SD & $M$ & SD & M & $\mathrm{SD}^{\prime}$ : \\
\hline Conceptual & .61 & .15 & .51 & .08 & .76 & .14 & .75 & .06 \\
\hline Perceptual & .53 & .22 & .47 & .11 & .72 & .16 & .76 & .14 \\
\hline Unrelated & .50 & .21 & .46 & .10 & .72 & .21 & .79 & .14 \\
\hline
\end{tabular}




\section{TABLE E}

Means and Standard Deviations for Number of Correctly Matched Pairs Grouped by Grade, Type and Stimulus

\begin{tabular}{|c|c|c|c|c|c|c|c|c|}
\hline \multirow{3}{*}{ stimulus } & \multicolumn{4}{|c|}{ Type 1} & \multicolumn{4}{|c|}{ Type 2} \\
\hline & \multicolumn{2}{|c|}{ Grade 1} & \multicolumn{2}{|c|}{ Grade 6} & \multicolumn{2}{|c|}{ Grade 1} & \multicolumn{2}{|c|}{ Grade 6} \\
\hline & $M$ & SD & $M$ & $S D$ & $M$ & SD & $\mathbf{M}$ & SD! : \\
\hline Conceptual & 4.71 & 2.01 & 5.42 & 2.31 & 2.92 & 1.97 & 4.21 & 2.08 \\
\hline Perceptual & 6.35 & 1.90 & 7.35 & 1.39 & 3.85 & 2.74 & 4.07 & 2.89 \\
\hline Unrelated & 2.64 & 1.00 & 4.50 & 1.74 & 1.35 & 1.08 & 1.71 & 1.26 \\
\hline
\end{tabular}


TABLE F

Means and Standard Deviations for Conceptual Pairs

Recalled Grouped by Grade, Type and Stimulus

\begin{tabular}{l|c|c|c|c|c|c|c|c}
\hline \multirow{2}{*}{ Stimulus } & \multicolumn{3}{|c|}{ Type 1 } & \multicolumn{4}{c}{ Type 2 } \\
\cline { 2 - 9 } & Grade 1 & \multicolumn{2}{|c|}{ Grade 6 } & \multicolumn{2}{c|}{ Grade 1 } & \multicolumn{2}{c}{ Grade 6 } \\
\cline { 2 - 8 } & $M$ & SD & $M$ & SD & $M$ & SD & M & SD \\
\hline Conceptual & 1.50 & 1.22 & 2.42 & 1.60 & .42 & .85 & .50 & .76 \\
\hline Perceptual & .14 & .36 & .35 & .63 & .07 & .26 & .07 & .26 \\
\hline Unrelated & .21 & .42 & .28 & .46 & .07 & .26 & .21 & .42 \\
\hline
\end{tabular}


TABLE G

Means and Standard Deviations for Perceptual Pairs

Recalled Grouped by Grade, Type and Stimulus

\begin{tabular}{|c|c|c|c|c|c|c|c|c|}
\hline \multirow{3}{*}{ stimulus } & \multicolumn{4}{|c|}{ Type 1} & \multicolumn{4}{|c|}{ Type 2} \\
\hline & \multicolumn{2}{|c|}{ Grade 1} & \multicolumn{2}{|c|}{ Grade 6} & \multicolumn{2}{|c|}{ Grade 1} & \multicolumn{2}{|c|}{ Grade 6} \\
\hline & $M$ & SD & M & $S D$ & M & SD & M & SD' \\
\hline Conceptual & .07 & .26 & .35 & .63 & .14 & .36 & .14 & .36 \\
\hline Perceptual & 1.35 & 1.00 & 2.78 & 1.88 & .64 & 1.08 & $\cdot 57$ & .75 \\
\hline Unrelated & .07 & .26 & .50 & .65 & .00 & .00 & .07 & .26 \\
\hline
\end{tabular}


TABLE H

Means and Standard Deviations for Unrelated Pairs Recalled Grouped by Grade, Type and Stimulus

\begin{tabular}{|c|c|c|c|c|c|c|c|c|}
\hline \multirow{3}{*}{ stimulus } & \multicolumn{4}{|c|}{ Type 1} & \multicolumn{4}{|c|}{ Type 2} \\
\hline & \multicolumn{2}{|c|}{ Grade 1} & \multicolumn{2}{|c|}{ Grade 6} & \multicolumn{2}{|c|}{ Grade 1} & \multicolumn{2}{|c|}{ Grade 6} \\
\hline & $M$ & SD & M & SD & $M$ & SD & M & SD' \\
\hline Conceptual & .00 & .00 & .21 & .57 & .21 & .42 & .07 & .26 \\
\hline Perceptual & .97 & .26 & .21 & .57 & .14 & .36 & .28 & .61 \\
\hline Unrelated & .71 & .91 & 2.21 & 1.42 & .42 & .75 & .14 & .36 \\
\hline
\end{tabular}


TABLE I

Means and Standard Deviations for Within Treatment Pairs Recalled Grouped by Grade, Type and Stimulus

\begin{tabular}{|c|c|c|c|c|c|c|c|c|}
\hline \multirow{3}{*}{ Stimulus } & \multicolumn{4}{|c|}{ Type 1} & \multicolumn{4}{|c|}{ Type 2} \\
\hline & \multicolumn{2}{|c|}{ Grade 1} & \multicolumn{2}{|c|}{ Grade 6} & \multicolumn{2}{|c|}{ Grade 1} & \multicolumn{2}{|c|}{ Grade 6} \\
\hline & M & SD & M & SD & $M$ & SD & M & SD' : \\
\hline Conceptual & $1 \cdot 50$ & 1.22 & 2.42 & 1.60 & .42 & .85 & .50 & .76 \\
\hline Perceptual & 1.35 & 1.00 & 2.78 & 1.88 & .64 & 1.08 & .57 & .75 \\
\hline Unrelated & .71 & .91 & 2.21 & 1.42 & .42 & .75 & .14 & .36 \\
\hline
\end{tabular}


TABLE J

Means and Standard Deviations for Latency Grouped by Grade, Type and Stimulus

\begin{tabular}{|c|c|c|c|c|c|c|c|c|}
\hline \multirow{3}{*}{ Stimulus } & \multicolumn{4}{|c|}{ Type 1} & \multicolumn{4}{|c|}{ Type 2} \\
\hline & \multicolumn{2}{|c|}{ Grade 1} & \multicolumn{2}{|c|}{ Grade 6} & \multicolumn{2}{|c|}{ Grade 1} & \multicolumn{2}{|c|}{ Grade 6} \\
\hline & M & SD & $\mathbf{M}$ & SD & $M$ & SD & M & SD' : \\
\hline Conceptual & 5.20 & 3.40 & 3.35 & $2 \cdot 52$ & 2.37 & 1.78 & $2 \cdot 51$ & 1.96 \\
\hline Perceptual & 4.22 & 4.16 & 3.62 & 2.99 & 3.11 & 2.16 & 2.58 & 2.59 \\
\hline Unrelated & $7 \cdot 38$ & 11.39 & 2.41 & 2.58 & 3.48 & 4.89 & 1.94 & 2.04 \\
\hline
\end{tabular}


TABLE K

Summary of Analyses of Variances

F Ratios for Dependent Variables

\begin{tabular}{c|c|c|c|c|c}
\hline \multirow{2}{*}{ Source } & \multirow{2}{*}{ df } & \multicolumn{4}{|c}{ Dependent Variables } \\
\cline { 2 - 6 } Sex (S) & 1 & .56 & .18 & .43 & .01 \\
\hline Grade (G) & 1 & $147.03 * * *$ & $89.42 * * *$ & $63.06 * * *$ & .62 \\
\hline Type (T) & 1 & 2.11 & $103.80 * * *$ & $78.64 * * *$ & $72.77 * * *$ \\
\hline Stimulus (ST) & 2 & .58 & 2.30 & .25 & .49 \\
\hline S X T & 1 & .01 & .03 & .01 & .01 \\
\hline S X G & 1 & $4.29 *$ & .01 & $10.09 * *$ & 4.01 \\
\hline
\end{tabular}

Note. $-\underline{N}=168$, within cell $\mathrm{df}=144$ for all analyses.

$* 0<05$

** $\mathrm{p}<01$

$* * * 0001$ 
TABLE K (continued)

Summary of Analyses of Variance,

E Ratiog for Dependent Variables

\begin{tabular}{|c|c|c|c|c|}
\hline \multirow{2}{*}{ Source } & \multirow{2}{*}{$\underline{\mathrm{df}}$} & \multicolumn{3}{|c|}{ Dependent Variables } \\
\hline & & Prtotal & Frconpr & Frperpr \\
\hline Sex (S) & 1 & 1.59 & .67 & .03 \\
\hline Grade (G) & 1 & $9.00 * *$ & $4.24 *$ & $8.25 * *$ \\
\hline Type (T) & 1 & $50.49 * * *$ & $26.50 * * *$ & $22.93 * * *$ \\
\hline Stimulus (ST) & 2 & $30.48 * * *$ & $35.69 * * *$ & $39.36 * * *$ \\
\hline$S X G$ & 1 & 1.59 & .67 & .03 \\
\hline $\mathrm{S} X \mathrm{~T}$ & 1 & .22 & 1.06 & .03 \\
\hline$G \times T$ & 1 & .89 & 2.07 & $8.25 * *$ \\
\hline
\end{tabular}


TABLE K (continued)

Summary of Analyses of Variance,

F Ratios for Dependent Variables

\begin{tabular}{c|c|c|c|c}
\hline \multirow{2}{*}{ Source } & \multirow{2}{*}{ df } & \multicolumn{3}{|c}{ Dependent Variables } \\
\cline { 3 - 5 } & & Frrotepr & Frtrpr & Frlat \\
\hline Sex (S) & 1 & .21 & .16 & .01 \\
\hline Grade (G) & 1 & $6.57^{*}$ & $11.31 * * *$ & $5.07^{*}$ \\
\hline Type (T) & 1 & $12.21 * * *$ & $60.88 * * *$ & $6.04 *$ \\
\hline Stimulus (ST) & 2 & $22.35^{* * *}$ & 2.45 & .17 \\
\hline S X G & 1 & 1.95 & 1.15 & .94 \\
\hline
\end{tabular}


TABLE K (continued)

Summary of Analyses of Variances

F Ratios for Dependent Variables

\begin{tabular}{c|l|l|l|l|l}
\hline \multirow{2}{*}{ Source } & \multirow{2}{*}{ df } & \multicolumn{4}{|c}{ Dependent Variables } \\
\cline { 3 - 6 } S X ST & & Frtotal & Frint & Frinc & Frprint \\
\hline G X ST & 2 & 1.64 & 1.47 & .48 & .77 \\
\hline T X ST & 2 & $3.19 *$ & 1.38 & 2.10 & .94 \\
\hline S X G X T & 1 & .04 & 3.13 & 2.52 & 2.82 \\
\hline S X G X ST & 2 & 1.89 & .09 & $3.82 *$ & 2.07 \\
\hline S X T X ST & 2 & 2.23 & 1.23 & 1.34 & .62 \\
\hline G X T X ST & 2 & .77 & .23 & .80 & .05 \\
\hline S X G X X ST & 2 & .09 & .02 & .40 & 1.08 \\
\hline
\end{tabular}


TABLE K (continued)

Summary of Analyses of Variance,

F Ratios for Dependent Variables

\begin{tabular}{|c|c|c|c|c|}
\hline \multirow{2}{*}{ Source } & \multirow{2}{*}{ df } & \multicolumn{3}{|c|}{ Dependent Variables } \\
\hline & & Prtotal & Frconpr & Frperpr \\
\hline $\mathbf{S} \times \mathbf{S T}$ & 2 & 1.71 & 2.11 & 1.38 \\
\hline G X ST & 2 & .25 & 1.28 & 1.73 \\
\hline $\mathrm{T} X \mathrm{ST}$ & 2 & 1.80 & $15.33^{* * *}$ & $12.39 * * *$ \\
\hline$S X G X T$ & 1 & 2.02 & 1.06 & .91 \\
\hline$S \times G \times S T$ & 2 & .52 & .13 & 1.00 \\
\hline $\mathrm{S} \times \mathrm{T} \times \mathrm{ST}$ & 2 & .22 & .96 & 1.49 \\
\hline$G \times T X S T$ & 2 & 1.01 & 1.41 & 2.50 \\
\hline$S \times G \times T \times S T$ & 2 & 1.02 & .64 & .01 \\
\hline
\end{tabular}


TABLE K (continued)

Summary of Analyses of Variance:

E Ratios for Dependent Variables

\begin{tabular}{c|c|c|c|c}
\hline \multirow{2}{*}{ Source } & & \multicolumn{3}{|c}{ Dependent Variables } \\
\cline { 3 - 5 } & & Frrotepr & Frtrpr & Frlat \\
\hline S X ST & 2 & .17 & 1.23 & .01 \\
\hline G X ST & 2 & 2.94 & .08 & 1.52 \\
\hline T X ST & 2 & $16.16 * * *$ & .33 & .22 \\
\hline S X G X T & 1 & 1.95 & .29 & .80 \\
\hline S X G X ST & 2 & .36 & .11 & .11 \\
\hline S X T X ST & 2 & .01 & .77 & .05 \\
\hline G X T X ST & 2 & $7.12 * *$ & .60 & .49 \\
\hline
\end{tabular}


TABLE I

Mean Number of Matching Errors Grouped by

Grade, Type and Error Type

\begin{tabular}{|c|c|c|c|c|}
\hline \multirow{2}{*}{$\begin{array}{c}\text { Error } \\
\text { Type }\end{array}$} & \multicolumn{2}{|c|}{ Type 1} & \multicolumn{2}{|c|}{ Type 2} \\
\hline & Grade 1 & Grade 6 & Grade 1 & Grade 6 \\
\hline Conceptual & .40 & .21 & .68 & .83 \\
\hline Perceptual & .38 & .35 & .69 & .30 \\
\hline Unrelated & .18 & .04 & .33 & .33 \\
\hline Other & 2.47 & 1.61 & 3.59 & 3.25 \\
\hline
\end{tabular}


REFERENCES

Ausubel, D. P. Educational psychology A cognitive view. New York, Holt, Rinehart and Winston, 1968.

Berlyne, D. E. Motivational problems raised by exploratory and epistemic behavior. In S. Koch (Ed.), Psychology: A study of a science. Vol. 5. New York, McGraw-Hill, 1963. Bousfield, W. A., Esterson, J., \& Whitmarsh, G. A. A study of developmental changes in conceptual and perceptual associative clusering. The Journal of Genetic Paychology, 1958, 92, 95-102.

Bruner, J. S. On cognitive growth I and II. In J. S. Bruner, R. R. Olver, \& P. M. Greenfield (Eds.), Studieg in cognitive growth. New York, John Wiley, 1966

Cramer, P. Idiodynamic sets as determinants of children's false recognition errorg. Developmental Peychology. $1974,10,86-92$.

Doyle, A. Iistening to distraction, A developmental study of selective attention. Journal of Experimental Child Pgychology. 1973, 15, 100-115.

Druker, J. F., \& Hagen, J. W. Developmental trends in the processing of task-relevant and tagk-irrelevent information. Child Development, 1969, 40, 371-382.

Entwisle, D. Word associations of young children. Baltimore: The Johns Hopkins Press, 1966. 
Fischer, G. J., \& Cook, M. B. Influence of distribution of practice and varying speeds of stimulus presentation on incidental learning. Psychological Reports, 1962, 10, $539-545$.

Flavell, J. H. Developmental studies of mediated memory. In H. W. Reese \& I. P. IIpsitt (Eds.), Advances in child development and behavior. Vol. 5. New Yorki Academic Press, 1970.

Hagen, J. W. The effect of distraction on selective attention. Child Development, 1967, 38, 685-694.

Hagen, J. W., \& Hale, G. H. The development of attention in children. In A. D. Pick (Ed.), Minnesota symposia on child psychology. Vol. 7. Minneapolis, Univ. of Minn. Press, 1973.

Hagen, J. W., Meacham, J. A., \& Mesibov, G. Verbal labeling, rehearsal, and short-term memory. Cognitive Pgychology, 1970, 1, 47-58.

Hagen, J. W., \& Sabo, R. A. A developmental study of selective attention. Merrill-Palmer Quarterly, 1967, 13, 159-172.

Hale, G. A., Miller, I. K., \& Sterenson, H. W. Incidental

leaming of 11 im content, A developmental study. Child Development. 1968, 39, 69-77.

Hale, G. A., \& Piper, R. A. Developmentel trends in children's incidental learning. Some critical stimulus differences. Developmental Paycholoxy. 1973, 8, 327-335.

Hale, G. A., \& Piper, R. A. The effect of pictorial integration on children's incidental learning. Developmental Psychology. $1974,10,847-851$. 
Jablonsk1, E. N. Free recall in children. Psychological Bulletin, 1974, in press.

Maccoby, E. E., \& Hagen, J. W. Effects of distraction upon central 78. incidental recall: Developmental trends. Journal of Experimental child Psychology, 1965, 2, 280-289. McLaughlin, B. "Intentional" and "incidental" learning in human subjects, The role of instructions and motiration. Psychological Bulletin, 1965, 63, 359-376. Meacham, J. A. The development of memory abilities in the Individual and society. Human Development, 1972, 15 , 205-228.

Miller, R. The use of concrete and abstract concepts by children and adults. Cognitions International Journal of Cognitive Pgychology. 1973, 2, 49-58. Moran, L. J., \& Swartz, J. D. Longitudinal study of cognitive dictionaries from ages nine to seventeen. Developmental Psychology, 1970, 3, 21-28.

Neimark, E\%, Slotnick, N. S., \& Ulrich, T. Development of memorization strategies. Developmental Psychology, $1971,5,427-432$.

Nelsser, U. Cognitive psychology. New York, Appleton-CenturyCrofts, 1967.

Olver, R. R., \& Hornsby, J. R. On equivalence. In J. S. Bruner, R. R. Olver, \& P. M. Greenfield (Bds.), Studies in cognitive growth. New York, John Wiley, 1966.

Palermo, D. S., \& Jenkins, J. J. Word association norms grade achool through college. Minneapolis, Oniversity of Minnesota Press, 1964. 
Penk, W. Developmental changes in idiodynamic set responses of children's word associations. Developmental Psychology, $1971,5,55-63$.

Postman, I. Short-term memory and incidental learning. In A. W. Melton (Ed.), Categories of human learning. New York, Academic Press, 1964.

Quartermain, D., \& Mangan, G. Role of relevance in incidental learning of verbal material. Perceptual and Motor Skills, $1959,9,255-258$.

Rosenberg, S. The influence of intentional learning on incidental learning. The Journal of General Pgychology, $1962,67,181$.

Sabo, R. A., \& Hagen, J. W. Color cues and rehearsal in short-term memory. Child Development, 44, 77-82.

Schucker, B. C. Incidental learning as a function of stimulus preference. Unpublished doctoral dissertation, Yeshiva University, 1972.

Siegel, A. W., \& Corsini, D. A. Attentional differences in children's incidental leaming. Journal of Educational Psychology, 1969, 60, 65-70.

SiegeI, A. W., \& Stevenson, H. W. Incidental learning, A dovelopmental study. Child Development, 1966, 37, 811-817. Thomdike, E. I., \& Lorge, I. The teacher's word book of 30,000 words. New Yorkı Teachers College, Columbia University, Bureau of Publications, 1944. vonWright, J. M. Relation between verbal recall and visual recognition of the same otimull by young children. Jourmal of Experimental Child Psychology, 1973, 15, 481-487. 
Wallace, W. P. Consistency of emission order in free recall. Journal of Verbal Learning and Verbal Behavior. 1970. 9. 58-68. Wheeler, R. J., \& Dusek, J. B. The effects of attentional and cognitive factors on children's incidental learning. Child Development, 1973, 44, 253-258.

White, R. W. Motivation reconsidered, The concept of competence. Psychological Review, 1959, 66, 297-333.

Wickens, C. D. Temporal limits of human information processing A developmental study. Psychological Bulletin, in press. Yussen, S, R., Gagne, E., Gargiulo, R., \& Kunen, S. The distinction between perceiving and memorizing in elementary school children. Child Development, 1974 , $547-551$ 